\title{
PRICES, OUTPUT AND HOURS: AN EMPIRICAL ANALYSIS BASED \\ ON A STICKY PRICE MODEL
}

\author{
Julio J. Rotemberg
}

Working Paper No. 4948

\section{NATIONAL BUREAU OF ECONOMIC RESEARCH 1050 Massachusetts Avenue \\ Cambridge, MA 02138 \\ December 1994}

I owe an enormous debt to Michael Woodford for his advice. I also wish to thank Roland Benabou and David Romer for comments and the NSF for research support. All errors are my own. This paper is part of NBER's research programs in Economic Fluctuations and Monetary Economics. Any opinions expressed are those of the author and not those of the National Bureau of Economic Research.

(c) 1994 by Julio J. Rotemberg. All rights reserved. Short sections of text, not to exceed two paragraphs, may be quoted without explicit permission provided that full credit, including $\odot$ notice, is given to the source. 


\title{
PRICES, OUTPUT AND HOURS: AN \\ EMPIRICAL ANALYSIS BASED \\ ON A STICKY PRICE MODEL
}

\begin{abstract}
I show that a simple sticky price model based on Rotemberg (1982) is consistent with a variety of facts concerning the correlation of prices, hours and output. In particular, I show that it is consistent with a negative correlation between the detrended levels of output and prices when the Beveridge-Nelson method is used to detrend both the price and output data. Such a correlation, i.e., a negative correlation between the predictable movements in output and the predictable movements in prices is present (and very strong) in U.S. data. Consistent with the model, this correlation is stronger than correlations between prices and hours of work. I also study the size of the predictable price movements that are associated with predictable output movements as well as the degree to which there are predictable movements in monetary aggregates associated with predictable movements in output. These facts are used to shed light on the degree to which the Federal Reserve has pursued a policy designed to stabilize expected inflation.
\end{abstract}

Julio J. Rotemberg Harvard Business School Morgan Hall 277 Soldiers Field Road Boston, MA 02163 and NBER 
This paper studies the connection between aggregate output, aggregate hours of work and the average level of prices. It considers a particularly simple model with sticky prices and shows that, even when it is subject only to monetary shocks, it reproduces many of the output-price and hours-price correlations found in U.S. data. Following Rotemberg and Woodford (1994), I pay special attention to the model's ability to reproduce the correlations between the predictable movements in prices, output and hours. The predictable movements in output are of interest in part because they correspond to a natural measure of cyclical (or detrended) output. In particular, the Beveridge-Nelson measure of cyclical output is nothing more than the difference between the current value of output and the value it is expected to have in the infinite future.

One of the predictions of the model that is consistent with post-war U.S. data is the strong negative correlation between predictable output and predictable price movements over long horizons. This is closely related to the negative correlation between the H-P filtered (as well as linearly detrended) series for output and prices found by Cooley and Ohanian (1991). They read their finding as suggesting that "the emphasis on developing models [such as those of Lucas (1973), Taylor (1980) and Fischer (1977)] may have been unnecessary". On the other hand, the simulations of Judd and Trehand (1994) show that monetary shocks can lead to the sort of negative correlations found by Cooley and Ohanian (1991) in a sticky price model based on McCallum (1990). My analysis complements Judd and Trehand (1994) since I show, analytically, that a simple sticky price model subject only to monetary shocks predicts a negative correlation between predictable price and output movements over long horizons.

The reason is the following. Given a sluggish instantaneous response of prices, a positive monetary shock at $t$ raises both prices and output at $t$. Assuming this monetary impulse has no long run effects on output, output is then forecasted to decline back to its steady state level. On the other hand, prices can be expected to continue rising until the rise in prices is approximately proportional to the rise in money itself. Thus, monetary impulses that lead to the expectation of output declines also lead to the expectation of price increases. 
This means that monetary impulses generate a negative correlation between expected price changes and expected output changes over long horizons.

One advantage of working with a specific model is that one can check its consistency with many different correlations of price, output and hours movements. ${ }^{1}$ I stress two other types of correlation between the price and output series. First, there is the correlation between unpredictable output and price movements. When subject exclusively to monetary shocks the model implies that the correlation between the unanticipated movements in these two series should be positive. In the data, this correlation is indeed positive, although it is quite small in size. Second, I study predictable movements in prices and output over relatively short horizons. While the correlation between predictable price and output changes over long horizons is negative, the correlation between revisions in the predictable movements in these series over the next quarter is actually positive. Thus, if one revises upwards one's estimate of output growth over the next quarter, one typically revises upwards one's estimate of inflation in the next quarter as well. I show that, for certain parameters, this too is consistent with the model.

This study is closely related to the traditional analysis of Phillips curves. This traditional analysis shows that high unemployment is associated with slow growth in average wages (Perry 1970) and prices (Gordon 1970). Assuming that employment reverts back towards its mean, a high unemployment rate is associated with subsequent falls in unemployment, and thus with rises in employment. Thus, presumably, the Gordon (1970) equation is consistent with the idea that large predicted increases in employment are associated with relatively small increases in prices.

The literature on the Phillips curve has changed considerably in the last two decades. In particular, studies of the empirical relationship of prices and real variables now typically involve vector autoregressions (See for example Sims (1986), Blanchard (1989), King and

\footnotetext{
${ }^{1}$ This is important because, not surprisingly, even the sign of the correlation of price and output movements depends on the filter that is employed. Thus, Chadha and Prasad (1994) and Yun (1994) show that, while the detrended price level is negatively correlated with the detrended output level, inflation is positively correlated with detrended output. King and Watson (1993) show, more generally, that the correlation between prices and output depends on the frequency filter than one applies to the two series.
} 
Watson (1994), Yun (1994)). In moving to VAR's, the focus of this literature has shifted towards structural interpretations of the VAR residuals and away from statements about the overall correlation of output and inflation (though, the correlations among innovations in these series has received a fair amount of attention). As many authors have pointed out, giving structural interpretations to the VAR innovations is difficult because it is often difficult to determine a priori which combination of endogenous variables will react first to any given shock. Thus I analyze a VAR's without attempting to identify structural disturbances. I also depart from the VAR literature in another respect. This literature treats each shock as being distinct not only in that the shocks are uncorrelated with each other (which is presumably a requirement of any set of "fundamental" shocks) but also in that the dynamic response of the economy to any one shock need not bear any resemblance to the dynamic response to any other. By contrast, this analysis focuses precisely on the "typical" way in which inflation co-moves with output and employment in the aftermath of shocks.

A related question I wish to answer is whether predictable price movements are more correlated with predictable output movements or with predictable movements in hours worked. In the original study by Phillips, inflation was related only to unemployment though subsequent studies like Gordon (1970) included output growth in their regressions as well. As long as monetary variability is not the only determinant of output movements, the model I present suggests that expected price growth over a long horizon should be more strongly (negatively) correlated with expected output growth than with expected hours growth. To see this, suppose that there is an expected change in technological opportunities that leads to an expected increase in output. With a passive monetary policy, this also leads to a decline in prices and thus to a negative comovement of expected price and output growth. On the other hand, there is no reason why this expected increase in technological opportunities should lead to the expectation of an increase in hours. Thus, the existence of this type of variability dampens the negative association between expected hours and price growth. I find that, in the data, the series for expected hours growth is indeed less correlated with expected price growth than is the series for expected output growth. 
The paper proceeds as follows. Section 1 presents a very stylized monetary model of business fluctuations. It shows that the model implies that innovations in output should be positively related to innovations in prices while predictable movements over long horizons should be negatively correlated. In Section 2, I present my basic method for constructing expected changes in prices and output, as well as revisions in these expected changes. I pay particular attention to revisions in expected output and price growth because revisions at different points in time are uncorrelated with each other. It is thus relatively easy to determine whether the revisions in output growth are significantly correlated with the revisions in inflation. By contrast, expected inflation and expected output growth are very serially correlated, as are the detrended price and output series of Cooley and Ohanian (1991). Thus the strength of the association between these series is harder to asses.

Section 3 is devoted to the analysis of the correlations between price and output movements. It is here that I show that, as the model implies, innovations in prices and output are positively correlated. Revisions in predictable movements over long horizons are negatively correlated while revisions over a one quarter horizon are positively correlated.

Section 4 turns its attention to the correlation between price and hours changes. Section 5 is more speculative than the previous ones in that it provides a more general discussion of what the empirical findings suggest about monetary policy. While the earlier sections study only the degree to which the price-output correlations are consistent with a particular model, section 5 discusses the degree to which other models are consistent with the findings. In particular, I discuss two types of models. The first is the sort of model suggested by King and Plosser (1984) in which only real shocks affect output and the connection between prices and output is an artifice of the endogeneity of the money supply. According to King and Plosser (1984), output and prices rise together because money rises endogenously in response to real shocks that raise output.

The second class of models I consider is, once again, a class of models where the original impetus behind output changes may be non-monetary. The issue is then how monetary policy reacts to these shocks. To operationalize this question I compare the data to what 
would have occurred if the monetary authority set policy so that expected nominal GDP growth is constant. Under this counterfactual, a one percent expected increase in output would be associated with an expected price decline of one percent. The U.S. data that I study show instead that a one percent expected increase in output is associated with a larger expected decline in prices so that nominal GDP can be expected to fall as well. Consistent with this, predictable increases in output, particularly those over relatively long horizons, are generally associated with declines in the various measures of the quantity of money. Thus, the Federal Reserve appears to follow a policy of reducing the money supply (and thus inducing reductions in prices) during periods where output is expected to rise. As Rotemberg and Woodford (1994) show, the periods where output is most expected to rise are the bottoms of recessions. Thus, monetary policy is restrictive in these periods and this may prolong these recessions. The costs and benefits of this policy are discussed in the concluding section.

\section{A Simple Sticky Price Model}

In this section I present a simple model with sticky prices. This model is based on Rotemberg (1982) and Hairault and Portier (1992) in that it includes quadratic costs of changing prices as its source of nominal rigidity. ${ }^{2}$ The model is kept simple to the extreme, capital accumulation and many other aspects of the Hairault and Portier (1992) model are neglected. Hopefully this stripped down model shares the central implications of price rigidity so that similar implications would flow from other sticky price models such as those based on wage

\footnotetext{
${ }^{2}$ The model with quadratic costs of changing prices is equivalent, as far as the aggregates are concerned, to a model such as Calvo (1983) where in dividual firms have a constant hazard of adjusting their price. There is both microeconomic (Kashyap 1994) and macroeconomic (Caballero and Engel 1992) evidence against the constant hazard model. This evidence favors instead models where the probability (hazard) that a firm will change its price is increasing in the extent to which its existing price departs from its "desired" price. I would thus prefer to use such a non-constant hazard model. Unfortunately, only relatively restrictive models of this type have been solved to date. The most thoroughly studied case is Caplin and Leahy (1992) who analyze a model with fixed costs of changing prices in which money follows a random walk. This neglects serial correlation in money growth, which, from an empirical point of view, appears important. I thus use the quadratic cost model in the hope that the non-constant hazard models will eventually confirm the central predictions that are considered here. At least as far as monetary non-neutrality is concerned, the Caplin-Leahy (1992) model does confirm the earlier analysis based on quadratic costs.
} 
contracting of the form emphasized by Fischer (1977) and Taylor (1980).

There are $N$ infinitely-lived households, each of which produces one differentiated good. These differentiated goods are purchased by perfectly competitive firms that use them to produce final output according to the symmetric constant returns to scale production function:

$$
Y_{i t}=Y\left(z_{i t}^{1}, \ldots, z_{i t}^{N}\right)
$$

In this equation, $Y_{i t}$ represents the output of the perfectly competitive firm $i$, whereas $z_{i t}^{j}$ is its input of good $j$. Suppose that all firms (households) other than $j$ charge a price $P_{t}$ for their products at $t$. As shown for instance in Rotemberg and Woodford (1994), the symmetry and constant returns of (1) then imply that the aggregate demand for good $j$ at $t, Z_{t}^{j}$ is given by

$$
Z_{i}^{j}=\sum_{i} z_{i t}^{j} \quad \text { and } \quad Z_{t}^{j}=Y_{t} d\left(\frac{P_{t}^{j}}{P_{t}}\right)
$$

where

$$
Y_{t}=\sum_{i} Y_{i t}, \quad d(1)=1 \quad \text { and } \quad d^{\prime}(1)<0
$$

The production of differentiated good $j$ requires the labor of household $j$ according to the production function

$$
Z_{t}^{j}=X_{t} F\left(H_{t}^{j}\right), \quad F^{\prime}>0, F^{\prime \prime}<0
$$

where $H_{t}^{j}$ are the hours worked by household $j$ at time $t$ and $X_{t}$ is an index of the state of technology at $t$. The overall utility of household $j$ is given by

$$
U^{i}=E_{t} \sum_{k} \beta^{k}\left\{C_{t+k}^{j}-X_{t} v\left(H_{t+k}^{j}\right)-\frac{c X_{t}}{2}\left[\log \left(P_{t+k}^{j}\right)-\log \left(P_{t+k-1}^{j}\right)\right]^{2}\right\}
$$

This utility function embodies a number of assumptions that are meant to simplify the analysis. First, the linearity of utility as a function of consumption fixes the real rate at which future profits get discounted. Second, both the fact that the costs of changing prices are quadratic and that they do not reduce the output available for consumption simplify the analysis. The final simplification is that improvements in technology $X_{t}$ raise both the utility 
costs of working and the utility costs of raising prices. The simplest rationale for this is that the alternative to market production is production for home use and that home production has the same technical progress as production of market output. As a result, the disutility of work and the disutility from price changes rise with $X_{t}$. Like Greenwood, Rogerson and Wright's (1994) assumption that trend technical progress is the same in home and market production, this ensures that secular increases in $X_{t}$ do not lead to secular changes in hours worked.

At the symmetric equilibrium I consider, all households charge the same price $P_{t}$ for their output. Perfect competition then ensures that the output of the firms producing the final good with the production function (1) is sold at a price of $P_{t}$ as well. To ensure that monetary policy plays a role, I consider a simple cash-in-advance constraint of the form

$$
P_{t} C_{t}^{j} \leq M_{t}^{j}
$$

where $M_{t}^{j}$ is the amount of money household $j$ brings over from period $t-1$. In particular, the household's intertemporal budget constraint is given by

$$
M_{t+1}^{j}=P_{t}^{j} X_{t} F\left(H_{t}^{j}\right)+M_{t}^{j}-P_{t} C_{t}^{j}+T_{t+1}^{j}
$$

where $T_{t+1}^{j}$ are government transfers of money which are made in lump sum fashion. As long as the expected rate of price deflation from $\tau$ to $\tau+1$ is smaller than the discount rate (so that $E_{\tau}\left(\beta P_{\tau} / P_{\tau+1}\right)$ is smaller than one for all $\tau$ ), the household will choose to make the constraint (5) strictly binding. This means that, at a symmetric equilibrium where all prices are the same, the level of total purchases $Y_{t}$ must equal $M_{t} / P_{t}$. Since there is no reason in this model to produce anything other than the amount that is sold, the demand function (2) implies that

$$
H_{t}^{j}=F^{-1}\left(\frac{M_{t}}{P_{t} X_{t}} d\left(\frac{P_{t}^{j}}{P_{t}}\right)\right)
$$

This, coupled with (6) and the fact that (5) is binding imply that (4) can be written as

$$
\begin{gathered}
U^{i}=E_{t} \sum_{k} \beta^{k}\left\{\frac{P_{t+k-1}^{j}}{P_{t+k}} \frac{M_{t+k-1}}{P_{t+k-1}} d\left(\frac{P_{t+k-1}^{j}}{P_{t+k-1}}\right)+\frac{T_{t+k}^{j}}{P_{t+k}}-X_{t} v\left(F^{-1}\left(\frac{M_{t+k}}{P_{t+k} X_{t+k}} d\left(\frac{P_{t+k}^{j}}{P_{t+k}}\right)\right)\right)-\right. \\
\left.\frac{c X_{t}}{2}\left[\log \left(P_{t+k}^{j}\right)-\log \left(P_{t+k-1}^{j}\right)\right]^{2}\right\}
\end{gathered}
$$


In this equation, the only decision at $t$ which has an effect on utility is the choice of $P_{t}^{j}$. The optimal price is thus obtained by differentiating (8) with respect to this price. The resulting first order condition (evaluated at the symmetric equilibrium where $P_{t}^{j}$ is equal to $P_{t}$ ) is $E_{t}\left\{\frac{M_{t}}{P_{t} X_{t}} d(1)\left[\beta\left(d^{\prime}(1)+1\right) \frac{P_{t}}{P_{t+1}}-d^{\prime}(1) \frac{v^{\prime}}{F^{\prime}}\right]-c\left(\log \left(P_{t}\right)-\log \left(P_{t-1}\right)\right)+\frac{X_{t+1}}{X_{t}} \beta c\left(\log \left(P_{t+1}\right)-\log \left(P_{t}\right)\right)\right\}$

In the absence of costs of changing prices, i.e,when $c$ is equal to zero, this equation implies that $v^{\prime} / F^{\prime}$, which is the disutility of producing one additional unit, is equal to $\beta\left(d^{\prime}+1\right) \frac{P_{t}}{P_{t+1}} / d^{\prime}$. If the demand for each individual good is very elastic (so that $d^{\prime}$ is a large negative number), the discount factor is small (so $\beta$ is near one) and there is no inflation, this expression is near one. In this case, the marginal disutility of producing one unit of good $i$ is equal to the marginal utility of consuming one additional unit of the aggregate good. Imperfect substitutability of the goods implies that $d^{\prime}$ is larger (though it must be smaller than -1). It thus implies that the marginal disutility from producing an additional good must be smaller. This in turn implies that output is smaller since $v^{\prime}$ is increasing and $F^{\prime}$ is decreasing in hours worked. Thus, as usual, imperfect competition lowers aggregate output. As in Cooley and Hansen (1989), the model also implies that inflation reduces output because it acts as a tax on market activity (since households must hold cash for one period before they can consume).

Equation (9) makes $v^{\prime} / F^{\prime}$, which depends only on hours worked, a function of $M_{t} / P_{t} X_{t}$, $P_{t} / P_{t-1}$ and $X_{t} / X_{t-1}$. On the other hand, (7) implies that hours worked $H$ are a deterministic function of $M_{t} / P_{t} X_{t}$. Thus, (9) has a steady state solution in which hours and $M_{t} / P_{t} X_{t}$ are constant as long as $\left(\log \left(P_{t+1} / P_{t}\right)\right)$, and $\left(\log \left(X_{t+1} / X_{t}\right)\right)$ are constant. This steady state requires that money and technology grow deterministically at a constant rate. I assume instead that money growth and technology growth follow stationary stochastic processes. Because these processes are stationary, and assuming a stability condition spelled out below, the economy can be expected to remain near its deterministic steady state. This allows me to $\log$ linearize (9) around the steady state values of $\left(\log \left(M_{t} / P_{t} X_{t}\right)\right),\left(\log \left(P_{t+1} / P_{t}\right)\right)$, and $\left(\log \left(X_{t+1} / X_{t}\right)\right)$. When carrying out this $\log$ linearization I take into account that, because of (7), $v^{\prime} / F^{\prime}$ depends on $\left(M_{t} / P_{t} X_{t}\right)$. Ignoring constants, the loglinearized version of $(9)$ is then 
given by

$$
E_{t}\left[\left(p_{t+1}-p_{t}\right)+\gamma_{m}\left(m_{t}-p_{t}-x_{t}\right)-\gamma_{p}\left(p_{t}-p_{t-1}\right)+\gamma_{x}\left(x_{t}-x_{t-1}\right)\right]=0
$$

where lower case letters represent the logarithm of the respective upper case letters while $\gamma_{m}, \gamma_{p}$ and $\gamma_{x}$ are positive parameters. The first two of these parameters are functions of $\beta$, the steady state inflation rate, the elasticity of demand and the derivatives of $v^{\prime}$ and $F^{\prime}$ with respect to $H$. The third parameter, $\gamma_{x}$ is equal to $\beta c \pi(1+g)$ where $g$ is the average rate of growth of $X$ and $\pi$ is the average rate of growth of prices. Thus, $\gamma_{x}$ is zero if the average rate of inflation is zero. Given that the U.S. average inflation rate has been small and in the interest of simplicity, I thus set this parameter equal to zero in what follows.

Equation(10) is a second order difference equation in $p_{t}$ whose characteristic equation has two roots. As in Rotemberg (1982), this equation has a unique nonexplosive solution if one of these roots is smaller than one while the other is larger than one. As shown by Woodford (1986), the roots must also have this property for the unique solution to the linearized equation (10) to be approximately equal to the solution to (9). The solution then gives the price level at $t$ as

$$
p_{t}=\alpha p_{t-1}+(1-\alpha)(1-\delta) E_{t}\left\{\sum_{\tau=0}^{\infty} \delta^{j}\left(m_{t+j}-x_{t+j}\right)\right\}
$$

where $\alpha$ is the root smaller than one and $1 / \delta$ is the other root of the characteristic equation. The product of the two roots $\alpha / \delta$ plays a role below. This product is given by $\gamma_{p}$ which, using (9), equals $\frac{1}{\beta}-\beta \frac{M}{P X} \frac{d^{\prime}+1}{1+\pi}$ where $M / P X$ is the steady state value of $M_{t} / P_{t} X_{t}$. Since $d^{\prime}+1$ is negative and $\beta$ is smaller than one, this product of the roots is larger than one.

For illustrative purposes, I will be concerned with the case where $m_{\mathfrak{t}}$ is given by the following stochastic process:

$$
m_{t}-m_{t-1}=a\left(m_{t-1}-m_{t-2}\right)+\epsilon_{t}
$$

where $a$ is a parameter and $\epsilon_{t}$ is i.i.d. and I assume, initially, that $x$ is constant. The use of this stochastic process is not entirely arbitrary. Given (5), $m$ should be viewed as being the 
$\log$ of nominal GDP. It turns out that the evolution of this variable in post-war U.S. data is well described by (12) with $a$ being equal to $.45 .^{3}$

At first I assume that $\epsilon_{t}$ is the only shock affecting the economy at $t$. This is obviously counterfactual but it allows me to demonstrate that the signs of the correlations between price and output movements do not require any non-monetary shocks.

Using (12) and ignoring $x_{t},(11)$ becomes

$$
p_{t}=\alpha p_{t-1}+\frac{1-\alpha}{1-a \delta}\left(m_{t}-a \delta m_{t-1}\right)
$$

so that, using (12) once again, inflation at $t$ is given by

$$
\left(p_{t}-p_{t-1}\right)=\alpha\left(p_{t-1}-p_{t-2}\right)+\frac{(1-\alpha)}{1-a \delta}\left(\epsilon_{t}+a(1-\delta)\left(m_{t-1}-m_{t-2}\right)\right)
$$

On the other hand, the logarithm of output, $y_{t}$ equals $m_{t}-p_{t}$ so that (13) implies that

$$
y_{t}=\alpha y_{t-1}+\frac{\alpha-a \delta}{1-a \delta}\left(\epsilon_{t}+a\left(m_{t-1}-m_{t-2}\right)\right)
$$

Consider first the innovations in output and prices. The shock $\epsilon_{t}$ raises the price level by $\frac{1-\alpha}{1-a \delta} \epsilon_{t}$ and raises output by $\frac{\alpha-a \delta}{1-\alpha \delta} \epsilon_{t}$. As we saw above, the product of the two roots $\alpha / \delta$ exceeds one so that, as long as $a$ is smaller than one (which is required for the rate of growth of money to be stationary), prices and output move in the same direction. Thus the innovations in both series should be positively correlated.

Now consider the revisions at $t$ in the growth of output from $t$ onwards. Since $\epsilon_{t}$ has no long run effect on output in this model, output growth from $t$ to infinity is revised upwards by the extent of its initial decline, namely

$$
-\frac{\alpha-a \delta}{1-a \delta} \epsilon_{t}
$$

On the other hand, $\epsilon_{t}$ has a permanent effect on the level of the money supply. In particular, it raises the value that is expected for $m$ in the far future by $\epsilon_{t} /(1-a)$. The

\footnotetext{
${ }^{3}$ In particular, neither further lags of the change in nominal GDP nor a deterministic trend are statistically significant in a regression explaining the log difference in nominal GDP. It is also worth noting that both Rotemberg (1982) and Yun (1994) suggest that, with $a$ positive and equal to about .6, (12) is a parsimonious representation of the time series behavior of $\mathrm{Ml}$.
} 
long run neutrality of the shock thus implies that the price level rises eventually by the same amount. Given that the price level's initial rise equals $\frac{1-\alpha}{1-a \delta} \epsilon_{t}$ (which is less than $\epsilon$ itself), the revision at $t$ in expected price growth from $t$ to infinity equals

$$
\frac{a(1-\delta)+\alpha(1-a)}{(1-a)(1-a \delta)} \epsilon_{t}
$$

Since the coefficient of $\epsilon_{t}$ is positive in this expression, the expression is negatively correlated with the output growth revision in (16).

It is also of interest to gauge the empirical magnitude of this negative relation. In particular, I compute the amount by which the price revision rises when output growth is revised downwards by one percent. Continuing to assume that $\epsilon_{t}$ is the only shock at $t$, this is given by the negative of the ratio of the expression in (17) to the expression in (16). It thus equals

$$
\frac{a(1-\delta)+\alpha(1-a)}{(1-a)(\alpha-a \delta)}=1+\frac{a(1-a \delta)}{(1-a)(\alpha-a \delta)}
$$

which exceeds one as long as $a$ is strictly positive (whereas it equals one if $a$ is zero). As long as $a$ is positive, so that money is expected to continue rising after a positive $\epsilon$, price growth from $t$ onwards is revised upwards by more than output growth is revised downwards.

Up to this point, the analysis has covered only revisions in output and price growth because these are the objects on which I will focus the empirical analysis. But, it follows from (15) and (14) that the overall expectation of output growth from $t$ to infinity must be negatively correlated with the overall expectation of price growth over the same horizon (so that the Beveridge-Nelson detrended values of price and output are negatively correlated). To see this, note that (14) implies that positive lagged values of $\epsilon_{t}$ exert positive influences on current inflation. Similarly (15) implies that positive lagged values of $\epsilon_{t}$ exert a positive influence on the current level of output. Because output is always expected to return to its steady state level, this implies that positive lagged values of $\epsilon_{t}$ lead to expected reductions in output. Thus, for any positive $j, \epsilon_{t-j}$ causes expected movements in output from $t$ to infinity that have the opposite sign as the expected movements in price caused by the same $\epsilon_{t-j}$. The result is that these expected movements in price and output are negatively correlated 
I now turn my attention to revisions in output and price growth over shorter horizons. One reason for doing so is that these correlations can serve to distinguish this model empirically from competing monetary models. In particular the model implies that the correlation between these short term revisions can have the opposite sign as the correlation of revisions of price and output growth over long horizons. Consider in particular the revision at $t$ of output growth from $t$ to $t+1$. It follows from (15) that this equals

$$
[\alpha+a-1] \frac{\alpha-a \delta}{1-a \delta} \epsilon_{t}
$$

while the corresponding revision of price growth is

$$
[\alpha+a(1-\delta)] \frac{1-\alpha}{1-a \delta} \epsilon_{t}
$$

These two revisions are positively correlated as long as $(\alpha+a)$ exceeds one. When this condition is met a positive $\epsilon_{t}$ leads output to rise further from $t$ to $t+1$ before it reverts back to its steady state value. Thus a positive $\epsilon_{t}$ leads one to revise upwards one's forecast of both price and output growth over the next period. This prediction puts this model in sharp contrast with the monetary model of Christiano and Eichenbaum (1992). In that model, just like in this one, innovations in money at $t$ lead to increases in both output and prices at $t$ so that one can expect innovations in prices and output to be positively correlated. Moreover, that model also implies that prices keep rising after a monetary injection while output reverts back to normal so that revisions in output growth over long horizons are negatively correlated with revisions in price growth over analogous horizons. But, unlike this model, output is expected at $t$ to move monotonically back to the steady state. Thus, revisions in output growth over short horizons are also negatively correlated with revisions in price growth over short horizons.

Given that I have ignored changes in $X$, the above analysis applies as much to output as to hours changes. The reason is that (1) and (3) imply that the log of hours $h_{t}$ is given by

$$
f h_{t}=y_{t}-x_{t}
$$


where $f$ is a coefficient smaller than one. Thus, the model attributes differences in the correlation of $h$ and $y$ with prices to changes in $x$. In Section 3, I will focus only on the priceoutput correlations and see to what extent they are consistent with a model that involves no changes in $x$. Then, in Section 4, I turn to what the differences in the price-output and the price-hours correlations suggest about $x$.

Before closing this section, I discuss why the empirical analysis puts so much stress on the output, prices and hours while neglecting the empirical behavior of interest rates and monetary aggregates. The reason is that the model's implications for price-output correlations seem more robust, at least in some respects. In part this stems from the main objective of the model which is designed to explain how the rigidity of prices leads to output volatility. By contrast, the behavior of monetary aggregates and rates of return seems to hinge on aspects of the model that are more incidental.

Consider first the behavior of monetary aggregates. In Rotemberg (1982), I analyzed the empirical validity of a very similar model using the logarithm of M1 as a measure for $m$. While those results provide some support for the model, it is clear that the use of the level of M1 as an indicator of the degree to which monetary policy is expansionary has some shortcomings. First, a variety of different assets are used in a variety of different transactions so that it is unlikely that M1 (or any other simple sum monetary aggregate) measures the degree to which people have access to assets that facilitate transactions. Second, there are changes over time in the degree to which people use any particular set of assets, such as those in $\mathrm{M} 1$, for transactions. The resulting changes in velocity are often accommodated by the central bank. As a result, many of the movements in M1 represent reactions to velocity shifts (so that they require no changes in prices) rather than representing a change in the degree to which monetary policy is expansionary. To see the complication involved somewhat more formally suppose that the stock of money that is used to satisfy (5), $M_{t}$, consists of two components:

$$
M_{t}=M_{t}^{o}+M_{t}^{a}
$$

In this equation $M_{t}^{o}$ represents some published (or "official") money stock while $M_{t}^{a}$ 
represents money provided by the private sector in some form that is not measured. The existence of this alternative form of payment represents a simple (though not necessarily realistic) formalization of the idea that methods of payment other than money are available. 4 Suppose that there is a restriction on the supply of the alternative money $M_{t}^{a}$. I assume that only one agent can issue this money, that this agent cannot use this money for his own purchases and that he cannot offer to pay interest on this money. The supplier's intertemporal budget constraint is then

$$
M_{t+1}^{s o}=P_{t}^{s} X_{t} F\left(H_{t}^{s}\right)+M_{t}^{s o}-P_{t} C_{t}^{s}+T_{t+1}^{s}+M_{t+1}^{a}-M_{t}^{a}
$$

where $M_{t}^{s o}$ are the supplier's official money holdings at the beginning of $t+1$. Note that the supplier is forced to redeem units of the alternative money for the official one if people so demand it and that he benefits when people choose to hold more $M^{a} .{ }^{5}$

As far as rate of return is concerned, $M^{a}$ and $M^{\circ}$ are the same so households other than the issuer would seem to be indifferent between the two. I assume that there are some other characteristics of the assets which determine the fraction of each that they wish to hold. In particular, I assume that the household sector as a whole want a fraction $1 / V_{t}^{0}$ of their money to be part of the official money stock. Thus,

$$
M_{t}=M_{t}^{o} V_{t}^{o}
$$

Since (5) is binding, this implies that $V_{t}^{o}$ is the velocity of circulation of official money. There is, of course, no reason to assume that $V_{t}^{o}$ is constant. Its variations lead to variations in $M_{t}$ just as do variations in $M_{t}^{0}$. But, insofar as changes in official measures of the money stock respond to variations in $V_{t}^{o}$ in order to stabilize $M_{t}$, the connection between $M_{t}^{o}$ and both output and inflation is weakened.

Now consider the behavior of interest rates. King (1992) has criticized sticky price models for implying that an increase in the money supply leads to a counterfactual increase in

\footnotetext{
${ }^{4}$ See Lucas and Stokey (1987) for a more realistic model where some goods can be purchased on credit.

${ }^{5}$ The closest institutional analog for $M^{a}$ is the stock of gift certificates outstanding, but I prefer to interpret $M^{a}$ more broadly as an alternative transactions technology.
} 
interest rates. Such a criticism would seem to be particularly pertinent when addressed to the model presented here, since that model has a constant real rate at which people discount the future, namely $1 / \beta$. But, I will argue that the force of this criticism depends on what one assumes about the financial assets that are available to people. Thus, I start by showing that this criticism is indeed valid if people have access to a relatively rich menu of assets and if no asset other than money provides liquidity services. I then argue that, without making these explicit assumptions about the range of available assets, the model lacks testable implications for interest rates. To show the ambiguities involved, I provide a related model in the Appendix where increases in money lower short term nominal interest rates.

The cash in advance constraint restricts the menu of available assets to some extent. In particular, it rules out the existence of interest bearing assets in which people can invest their labor income at $t$ and use the proceeds for consumption at $t+1$. Such assets would dominate money and would thus lead people not to satisfy (5). However the model is, in principle, compatible with the existence of an asset in which people can invest one dollar of their labor income at $t$ and get $P_{t+2} /\left(P_{t+1} \beta\right)$ dollars at $t+1$ which, after being exchanged for money at $t+1$, can be used for consumption at $t+2$. The result is that a dollar invested in this asset at $t$ yields $1 / \beta P_{t+1}$ units of consumption at $t+2$. Since a dollar invested in money at $t$ yields $1 / P_{t+1}$ units of consumption at $t+1$, agents are indifferent between the two assets. Thus, $P_{t+2} /\left(P_{t+1} \beta\right)$ is the dollar rate of return between $t$ and $t+1$ on a nonmonetary asset which, in equilibrium, won't actually be traded. As we saw, a shock $\epsilon_{t}$ that raises output temporarily also leads to a protracted periods of higher inflation. Such a shock would thus lead to an increase in the nominal return of this asset. By contrast, it is widely accepted that interest rates fall when monetary policy becomes expansionary.

This counterfactual implication hinges on several aspects of the model that are not really central. First, if utility is made concave in consumption (rather than linear), then the expansion in output induced by the monetary expansion also leads to a fall in real interest rates. In Jeanne's (1994) sticky price model, this also leads to a fall in nominal interest rates 
as long as the intertemporal elasticity of substitution of consumption is smaller than one and monetary shocks are serially independent.

Second, the model does not incorporate any financial market distortions. In fact, the model gives no direct role to financial assets other than money; such assets are in zero net supply and are not traded in equilibrium. It is possible to price such assets, as I have done above, by setting their price in such a way that people are indifferent with respect to holding them. But the resulting price, and thus the behavior of interest rates, is obviously sensitive to the existence of financial market distortions. Moreover, adding financial market distortions to the model would affect the price of the assets that are not traded in equilibrium (and thus interest rates) but might well have no effect on either production or the price of goods in terms of money. Thus, the interest rate implications of the model are not central.

If one were to amend the model so that it incorporates realistic asset markets, one would want to add financial market distortions which ensure that stocks and bonds have different expected yields, (i.e,the Mehra-Prescott puzzle). Of even greater relevance to the issues at hand, one would want a model in which the equity premium is related to changes in inflation rates. ${ }^{6}$ Constructing a realistic model where inflation affects the differential between expected rates of return is well beyond the scope of this paper. In the Appendix, I do construct a very simple model where bond returns are smaller than stock returns on average and where, in addition, increases in money lower the nominal return on bonds. This model is offered not for the realism of the financial market imperfections that it incorporates but because it illustrates that the class of models under study has fragile interest rate implications.

\section{Basic Methodology}

In this section, I show how I compute forecasted price, output and hours changes. To carry out this computation, I must first choose the information set on which these forecasts will be based. It might be thought that the model itself could be used to guide this choice. However,

\footnotetext{
${ }^{6}$ See Blanchard (1993) and the references cited therein. Increases in inflation seem to raise the rate of return on stocks relative to that of bonds.
} 
the model is not meant to be complete so that it does not include all the factors that ought to help in forecasting output, prices and hours. Rather, my aim is to ask whether this simple model can account for the correlations among the forecastable movements that are actually present in the data. This suggests that I use an information set that includes more variables than those present in the model. Actually, the model itself is quite consistent with the use of a fairly rich information set as long as there are forecastable variations in $x_{t}$. The reason is that the model is silent as to which variables might be correlated with these forecastable movements. Moreover, the assumed process for the evolution of $m,(12)$ is meant only as an approximation that facilitates the theoretical discussion. If one ignores this equation, the model suggests that any variable that helps in forecasting $m$ should help forecast prices and output and thus deserves to be included.

These considerations suggest that one should use a VAR to construct expected changes in the various series (as opposed to say, using univariate forecasting equations). But, one must be careful not to include too many variables in the VAR that is used for forecasting. Doing so would lead one's forecasts to be contaminated by overfitting so that the correlations between the various forecasted series would be unreliable. A final consideration is that I seek properties of the forecasted price, output and hours series that are robust to changes in the information set used for forecasting. This is particularly important because it is both unclear exactly which variables ought to be used for forecasting and it is dangerous to simply include all the variables that are possibly relevant.

Two variables that obviuosly need to be included in the VAR are the change in output, $\Delta y_{t}$, and the change in prices $\Delta p_{t} .{ }^{7}$ Following Rotemberg and Woodford (1994) I use value added in the private sector as my output series and let the corresponding deflator represent prices. Because they have been shown to predict output growth by numerous authors, I always include also the ratio of consumption to output, $\left(c_{t}-y_{t}\right)$ and the detrended level of hours $h_{t} .{ }^{8}$ Moreover, as Rotemberg and Woodford (1994) show, the standard real business

\footnotetext{
${ }^{7}$ These are included in first differences because it is quite likely that their levels are not stationary.

${ }^{8}$ The exact definition of the variables is the same as in Rotemberg and Woodford (1994) where we argue that they are particularly good at forecasting output. Consumption is given by consumer expenditure on
} 
cycle model suggests that these variables should help forecast output growth.

In the hope of obtianing robuts results, I experimented with several candidates for a fifth included variable. These included two interest rates, namely the federal funds rate and the interest rate on 6-month commercial paper. Because the results were so similar, I report only the results obtained with the federal funds rate, which is labelled $i$. I also experimented with the log changes of four measures of the stock of money. These are the log change in the monetary base, $\Delta \mathrm{M}_{B t}$, the log change in $\mathrm{M} 1, \Delta \mathrm{M}_{1 t}$, the log change in $\mathrm{M} 2, \Delta \mathrm{M}_{2 t}$ and the log change in the CE monetary aggregate of Rotemberg, Driscoll and Poterba (1994), $\Delta \mathrm{M}_{C t}{ }^{9}$ $\mathrm{My}$ reason for including monetary aggregates is that these may contain information about movements in $m_{t}$ (although, for the reasons discussed above, movements in these aggregates are unlikely to be identical to movements in $m_{t}$. Interest rates, on the other hand, are useful indicators of $m_{t}$ in the variant discussed in the Appendix. I also considered a VAR in which the 5 th variable is not related to financial markets at all but consists instead of log of the share of labor compensation in the value added of the corporate business sector, $s_{H}$. There are two reasons to include this variable, both of which relate to more complex models where labor and capital are separate inputs. First, including this variable means that I am allowing lagged changes in wages to have an independent effect on price and output changes. Second, the labor share is an indicator of the level of markups in the economy. And one might well imagine that a high level of markups, which Rotemberg and Woodford (1991) show to be associated with low output, is also associated with a reduction in markups over time. If this were the case, high markups would be correlated with subsequent reductions in prices. ${ }^{10}$

Before running a VAR with these variables, one has to make sure that these variables are stationary. Rotemberg and Woodford (1994) report Dickey-Fuller test statistics that

nondurables and services while hours are measured as man-hours in the private non-agricultural sector. For earlier uses of the consumption share, see Campbell (1987) and Cochrane and Sbordone (1988); for that of labor market indicators, see Blanchard and Quah (1989) and Evans 1989.

${ }^{9}$ As they show there are several ways of constructing the weights in the CE aggregate. Here I use their preferred specification which constructs the weights using an ARIMA model and which they call ARIMA CE-3.

${ }^{10}$ I obtained essentially identical results when, instead, I used either the log of the price of crude oil or the log of the Commodity Research Bureau's index of commodity prices as my fifth variable. I considered these because commodity prices are often regarded as useful in forecasting the growth of finished goods prices. 
show that one can reject the existence of a unit root in the time series for $\Delta y_{t}, c_{t}-y_{t}$ and $h_{t}$. Rotemberg, Driscoll and Poterba (1994) report results suggesting that M1, M2 and the monetary base have unit roots, though their first difference does not, which is why these are included in first differences. The CE aggregate may actually be stationary in levels though $I$ include it in first differences as well for comparability. Dickey-Fuller tests (not reported) also suggest that the interest rates and my measure of the labor share are stationary. ${ }^{11}$

This leaves the question of how many lags to include in the VAR. Rotemberg and Woodford (1994) found that including more than two lags of the first three variables I am using in this study leads to statistically insignificant coefficients. Similarly, lags beyond the second do not contribute important explanatory power in the larger systems considered here. Thus, only two lags are included. ${ }^{12}$

Hence the VAR specification is

$$
Z_{t}=A Z_{t-1}+\epsilon_{t}
$$

where

$$
Z_{t}=\left(\begin{array}{c}
\Delta y_{t} \\
\left(c_{t}-y_{t}\right) \\
h_{t} \\
\Delta p_{t} \\
z_{t}^{5} \\
\Delta y_{t-1} \\
\left(c_{t-1}-y_{t-1}\right) \\
h_{t-1} \\
\Delta p_{t-1} \\
z_{t-1}^{5}
\end{array}\right) \quad \text { and } \quad \epsilon_{t}=\left(\begin{array}{c}
\epsilon_{t}^{y} \\
\epsilon_{t}^{c y} \\
\epsilon_{t}^{h} \\
\epsilon_{t}^{p} \\
\epsilon_{t}^{5} \\
0 \\
0 \\
0 \\
0 \\
0
\end{array}\right)
$$

and only the five three rows of $A$ need to be estimated. The residuals are labeled in such

\footnotetext{
"On the other hand, the income velocity of my monetary aggregates, and in particular that of the monetary base and of M1, do not appear stationary. The income velocity of M2 has been viewed as stationary until recently but the recent movements in M2 suggest that this stationarity was probably spurious. Because of this lack of stationarity, I did not include velocity measures in the VAR. Note that the variant of the model that uses (20) and (22) is completely consistent with nonstationary movements in velocity.

${ }^{12}$ Note that, unlike what occurred in the three variable system of Rotemberg and Woodford (1994), many of the coefficients in this larger system are statistically insignificant. This means that these coefficient estimates probably have more sampling noise than the coefficients of the simplest VAR that is able to capture the salient correlations in the data. However, this sampling noise is probably inevitable if one wishes to treat symmetrically all the variables in a larger system.
} 
a way that the innovation in $y_{t}$ is denoted by $\epsilon_{t}^{y}$, and similarly for the innovations in the other variables. The variable $z_{t}^{5}$ is left unspecified at this point because, as explained above, I considered several candidates.

When $z^{5}$ is given by an interest rate, it is statistically significant in the equation explaining inflation (with $\mathrm{t}$-statistics on the two coefficients that exceed 2) but the money stock measures are much less significant. Of the money stock measures, the one with the most statistically significant coefficient is the CE measure. ${ }^{13}$ The other measures of money growth never have $t$-statistics exceeding 1.49 in the equations explaining inflation, and F-tests accept the hypothesis that one can exclude these from the inflation equation altogether. On the other hand, if one already includes the federal funds rate in the VAR and also considers adding a sixth variable representing money growth, the one that has the most statistically significant coefficient is the monetary base. Even though its highest $t$-statistic is 1.67 and an F-test allows one to accept the hypothesis that it does not belong in the regression explaining inflation, I also consider also a six variable VAR that includes both the federal funds rate and the monetary base. Unlike the money growth variables, the labor share $s_{H}$ is a statistically significant predictor of inflation; after including lags of the $\Delta y, c-y, h$ and $\Delta p$ variables the $t$-statistic of the lagged labor share variable in the equation explaining inflation is 2.32 . Consistent with the view that a high labor share means that markups are high so that prices must fall to bring markups back to their steady state value, high values of $s_{H}$ (which represent low markups) are associated with higher levels of subsequent inflation.

As in Rotemberg and Woodford (1994), (23) can be used to construct expected changes in the various variables. For any variable $z, \mathrm{I}$ denote the amount by which it is expected at $t$ to grow between $t$ and $t+k$ by $\widehat{\Delta z}_{t}^{k}$. In the case of output, for example, this expected growth is given by

$$
\widehat{\Delta y}_{t}^{k}=B_{y}^{k} Z_{t} \quad B_{y}^{k} \equiv e_{1}^{\prime}\left(A+A^{2}+A^{3}+\ldots+A^{k}\right)
$$

where $e_{1}$ is a vector that has a one in the first position and zeros in all others. For the case where $k=\infty$, we have (minus) the Beveridge-Nelson definition of the cyclical component of

\footnotetext{
${ }^{13}$ One of its the corresponding coefficients in the equation explaining inflation has a t-statistic of 1.92
} 
$\log Y_{t}$, which is given by

$$
\widehat{\Delta y}_{t}^{\infty}=B_{y}^{\infty} Z_{t} \equiv e_{1}^{\prime}(I-A)^{-1} A Z_{t}
$$

One can use analogous formulas to compute expected changes in prices. These are given by

$$
\widehat{\Delta p}_{t}^{k}=B_{p}^{k} Z_{t}
$$

where $B_{p}^{k}$ is computed like $B_{y}^{k}$ except that $e_{1}$ is replaced by $e_{4}$, a vector with a one in the fourth position and zeros in all the others. Similar formulas apply for computing expected changes in the money stock. A slightly different formula applies when one wishes to compute the expected changes of variables that enter as levels in the VAR. For example, the expected growth of hours is given by

$$
\widehat{\Delta h}_{t}^{k}=B_{h}^{k} Z_{t} \equiv e_{3}^{\prime} A^{k} Z_{t}-h_{t}
$$

where $e_{3}$ is defined analogously to $e_{1}$ and $e_{4}$ while the second equality defines $B_{h}^{k}$. A similar formula applies if one wishes to compute expected changes in interest rates or in the labor share. Note that, because the variables that enter as levels are stationary, their expected change over an infinite horizon is simply the negative of their current value.

Because the variables in $Z_{t}$ are serially correlated, the expected changes computed as in (24), (25) and (26) are serially correlated as well. For some purposes, namely to draw statistical inferences about the strength of the relationship between the expected growth rates of various variables, it is better to deal with the part of the expected growth that is uncorrelated over time. This lack of correlation over time is a property of the revisions in expected growth rates. To calculate revisions, it is useful to start with the growth of a variable $z$ that is expected at $t$ to take place between $t+j$ and $t+j+k$. Let this growth over $k$ periods be denoted by $\widehat{\Delta z}_{j, t}^{k}$. It equals

$$
\begin{aligned}
\widehat{\Delta x}_{j, t}^{k} & \equiv E_{t}\left[x_{t+j+k}-x_{t+j}\right] \\
& =\widehat{\Delta x}_{t}^{k+j}-\widehat{\Delta x}_{t}^{j} \\
& =\left(B_{x}^{k+j}-B_{x}^{j}\right) Z_{t}
\end{aligned}
$$


where $B_{x}^{k}$ represents the matrix that corresponds to variable $x$ and that is constructed as in $(24),(25)$ or $(26)$.

Let $\widetilde{\Delta x}_{t}^{k}$ denote the revision at $t$ in $x$ 's expected growth over the next $k$ periods. In other words it is

$$
\widetilde{\Delta x}_{t}^{k} \equiv E_{t}\left(x_{t+k}-x_{t}\right)-E_{t-1}\left(x_{t+k}-x_{t}\right)
$$

Using (27), this equals

$$
\widetilde{\Delta x}_{t}^{k}=B_{x}^{k} Z_{t}-\left(B_{x}^{k+1}-B_{x}^{1}\right) Z_{t-1}
$$

As an illustration, the formula for the revision in output growth using (24) to substitute for the $B$ 's in the above equation is

$$
{\widetilde{\Delta y_{t}}}^{k}=e_{1}^{\prime} R^{k}\left(Z_{t}-A Z_{t-1}\right) \quad \text { where } \quad R^{k}=\left(A+A^{2}+A^{3}+\ldots+A^{k}\right)
$$

Note that $\left(Z_{t}-A Z_{t-1}\right)$ is the vector of innovations, which are uncorrelated. So, indeed, the revisions are uncorrelated over time. Note also, that the revision of price changes differs from that in (28) only in that one must use $e_{4}$ instead of $e_{1}$.

I will be concerned with the relationship between the revisions for different variables. Letting $V$ denote the variance covariance matrix of $Z_{t}$, the covariance of $\widetilde{\Delta y}_{t}^{k}$ and $\widetilde{\Delta p}_{t}^{k}$ is

$$
e_{1}^{\prime} R^{k}\left[V-A^{\prime} V A^{\prime}\right] R^{k \prime} e_{5}
$$

and similar equations give the variances of these revisions as well as the covariances between other revisions. Note also that the covariance between the output and inflation innovation is given by (29) but with $R^{k}$ replaced by the identity matrix.

A different measure of association is the regression of the revision in one variable on the revision in another. As discussed below, I will be particularly interested in the coefficient of a regression of $\widetilde{\Delta p}_{t}^{k}$ on $\widetilde{\Delta y}_{t}^{k}$. This equals

$$
\frac{e_{1}^{\prime} R^{k}\left[V-A^{\prime} V A^{\prime}\right] R^{k \prime} e_{5}}{e_{1}^{\prime} R^{k}\left[V-A^{\prime} V A^{\prime}\right] R^{k \prime} e_{1}}
$$

Both the measure of association in (29) and that in (30) depend on the parameters in $A$ and these are not estimated precisely. As in Rotemberg and Woodford (1994), I compute 
a measure of the uncertainty in these measures that is due to the sampling uncertainty associated with the estimated coefficients in the VAR. This is done as follows. For each measure of the type in (29) and that in (30) I compute the vector of derivatives $D$ with respect to the elements of $A$. The variance of my measure is then $D^{\prime} \Omega D$ where $\Omega$ is the variance-covariance matrix of the elements of $A$.

\section{Price and Output Movements}

The basic results concerning price and output are presented in Table 1. The columns represent specifications that differ in the variables that are included in the VAR. The last column, in particular, displays results using a six variable VAR that includes the federal funds rate and the monetary base. The others include just five variables and the column header gives the name of the included variable. The first two rows give the standard deviations of the output and inflation innovations while the third row gives the correlation between these innovations. In each case, standard errors are displayed below the estimates where, as explained above, these standard errors are based on the sampling variance of $A$. The correlation between the output and inflation innovations are consistently positive. This is consistent with the predictions of the monetary model of section 1, although the correlations are much smaller in absolute magnitude than those predicted by that model.

Similar results have been found by others. While not couched in the language of VAR's, the econometric equation of Gordon (1980) also shows a strong contemporaneous positive relation between output changes and price changes. Similarly, King and Watson (1994) analyze a two variable VAR consisting of unemployment and inflation and show that their innovations are negatively correlated. Since unemployment and output tend to move in opposite directions, this too suggests a positive comovement between price and output innovations.

The next three rows give the analogous properties in the revisions for the growth between $t$ and infinity of prices and output. Interestingly, the standard deviations of predicted changes do not depend very much on the specification. All these specifications thus generate about the same amount of predictable movements. In all cases, the standard deviation of the 
expected growth of output is somewhat larger than the standard deviation of the output innovation. In the case of the predicted growth of prices, the revision has a much larger standard deviation than the innovation. In fact, the standard deviation of the inflation innovation is about half as large as the innovation in output whereas the standard deviation of the revision in expected inflation is about twice as large as the revision in expected output growth. Thus, a much larger fraction of price movements is forecastable.

The sixth row gives the key finding, namely that the correlation between the two revisions is negative, as the model of section 1 predicts. Interestingly, this correlation is much larger in absolute value than the correlation of the innovations. In all the specifications this correlation is smaller than -.64 (whereas the correlation between the innovations equals about .08). The overall picture that emerges is the following. An upwards revisions in current activity leads to current increases in prices. Moreover, as the eighth line of Table 1 shows, upwards revisions in current economic activity are associated with downwards revisions in the expected future growth of output. And, these downwards revisions in future output growth are themselves associated with future increases in prices. Thus upwards movements in current activity are associated with both current and expected future inflation.

The model implies, and the data are consistent with, a negative correlation between detrended output and prices when the Beveridge-Nelson method is used for detrending. This still leaves the question of whether one gets even stronger correlations using the methods of Cooley and Ohanian(1991), i.e. using either linear or Hodrick-Prescott trends. To analyze this I use formulas like (24), (25) and (28) to construct sample paths for expected movements in prices and output as well as sample paths for the revisions.

It should be said at the outset that the predicted output movements from the 5 variable VARs considered here are essentially identical to those from the 3 variable VAR considered in Rotemberg and Woodford (1994). For an illustration of this point, we display in Figure 1 the expected growth of output from $t$ to infinity from Rotemberg and Woodford (1994) as well as the results of applying (24) to the 5 variable VAR that includes the federal funds rate. Even though more variables are included in the present study and the sample of estimation 
is different (because the data for the Rotemberg and Woodford 1994 study start in 1948) the two series agree on all important respects and are highly correlated with each other. In both cases, the bottoms of recessions as defined by the NBER correspond closely to the dates where expected output growth is highest (because the economy has the most ground to recover).

Figure 2 displays the series for both predicted output growth and predicted price growth from $t$ to infinity from this same 5 variable system. The figure makes it clear that these are negatively correlated and their correlation, -.75, exceeds any of the correlations found by Cooley and Ohanian (1991) for either linearly detrended or Hodrick-Prescott filtered data. The figure also shows some particular episodes that may be informative. The 1980 recession both increased expected output growth and reduced expected inflation. But, it is really the 1982 recession, which is widely attributed to contractionary monetary policy, that brought on the highest level of expected output growth and nearly the lowest level of expected price growth. This suggest that monetary policy, and not supply shocks, are at least partly responsible for the negative correlation between expected output and price growth.

I now turn to an analysis of the sample paths of the revisions in expected price and output growth from $t$ to infinity. Figure 3 provides a scatter diagram of these revisions for the system that uses the federal funds rate. As the results in Table 1 indicate, the fit is fairly tight. Moreover, as is already suggested by Figure 2, this tight connection is not just the result of the behavior of prices and output over a particular subperiod. Instead, they are features of the entire period under analysis. Evidence of this can be found in Table 2 which displays the correlation of the revisions in output and prices for both the pre-1974 and the post-1974 period. These correlations are very similar. Whether the post-1974 correlations are larger or smaller than the pre-1974 correlations depends on which variable is included as $z_{5}$, but the correlations are similar (and substantial) in all cases.

Before closing this section, I turn my attention to the last six rows of Table 1, which also provide some evidence consistent with the model of section 1 . Row 7 reports the regression 
coefficient of the revision in price growth from $t$ to infinity on the corresponding revision in output growth. This is a measure of the relative size of price and output revisions in response to shocks. If the model, including the money supply rule (12), were completely correct, price and output revisions would be perfectly correlated and there would be no need to run a regression to compare their relative size. However, it is more reasonable to treat the money supply rule (12) as an average, or typical, rule. Thus, people sometimes have information that lead them to expect higher money growth than given by (12) while other times their information indicates smaller growth. As long as this information concerns changes in money in the distant future, the price growth revisions are more affected by the randomness of policy than the output growth revisions. The reason is that output in the infinite future is unrelated to this randomness and current output responds only slightly if money is affected only in the distant future. Thus the existence of this sort of randomness justifies measuring the effect of a typical monetary disturbance on the relative size of the two revisions by running a regression of price revisions on output revisions.

The results in row 7 indicate that a one percent increase in expected output growth lowers expected price growth by more than one percent. This larger responsiveness of price revisions than output revisions is consistent with (18) as long as $a$ is strictly positive.

Rows 8 and 9 focus on the correlations between revisions in price and output growth over shorter horizons. Row 9 reveals that the correlation between revisions in price and output growth over 10 quarters is negative and similar in size to the correlation of the corresponding revisions over an infinite horizon. On the other hand, row 8 shows that the correlation of output and price growth revision over the next quarter (i.e,between $t$ and $t+1$ ) is actually positive. As discussed earlier, this difference in between short and long horizon revisions is consistent with the model of section 1 as long as $a$ is positive so that money growth is positively serially correlated. In this case, positive monetary innovations at $t$ lead price and output to continue to rise between $t$ and $t+1$.

Rows 10 and 11 focus on the correlation between output innovations at $t$ and revisions in expected output growth from $t$ on. Row 10 shows that, for all specifications, these 
two magnitudes are negatively correlated. This is exactly what the model predicts since, according to the model, all innovations in output affect output only transitorily. Thus, positive innovations must be followed by declines in output of the same magnitude. The 11 th row focuses precisely on the question of whether the downwards revision in expected output growth has the same magnitude as the innovation in output. It reports the regression coefficient (computed as in (30) of the revision at $t$ of output growth from $t$ to infinity on the innovation in output at $t$. Whereas the model predicts this to equal -1 , the point estimates are somewhat lower than this. ${ }^{14}$ Finally, the last row shows that, as the model also implies, revisions in expected price growth are positively associated with the current innovation in inflation.

\section{Output versus Hours}

In most of the development of section 1 , I ignored variations in $x_{t}$ so that output and hours were perfectly correlated. In practice, this correlation is not perfect although Rotemberg and Woodford (1994) show that indeed, expected hours growth are highly correlated with expected output growth. Moreover, since hours are stationary, expected hours growth over a long horizon are simply equal to (minus) the current detrended level of hours. Thus, a high current level of hours should be associated with expected output declines. Since expected output declines are associated with high expected inflation, one would expect high hours to be associated with high expected inflation as well. Replacing high hours with low unemployment, this is precisely the sort of the correlation emphasized in the Phillips curve.

In this section, I pursue further the analysis of the connection between labor market indicators and inflation. I emphasize mostly the connection with detrended man-hours because Rotemberg and Woodford (1994) show that these are more strongly linked to expected output growth (while also playing a clearer role in the model under study). The empirical connection between unemployment and inflation is taken up only at the end of the section.

\footnotetext{
${ }^{14}$ This is consistent with Shapiro and Watson's (1988) finding that the innovation in the "permanent" component of output (i.e, in the Beveridge-Nelson trend level of output) is associated with declines in current output.
} 
Before presenting the empirical results, I use (19) to discuss how the model's implications for price-hours correlations differ from those for price-output correlations when $x_{t}$ is allowed to vary. ${ }^{15}$ For illustration, I consider two types of variations in $x_{t}$. The first is an unexpected change in $x_{t}$ that is expected to persist forever; this shock raises current productivity by the same amount as it raises future productivity. Only shocks of this type are entertained when it is assumed that technology follows a random walk. Second, I'll consider what happens when information is revealed at $t$ that $x$ will grow in the future. I will show that the existence of shocks of the first kind (in a model where there are still monetary shocks of the kind considered earlier) leads hours and price innovations to be more positively correlated than output and price innovations. The presence of the second type of shock implies that the negative correlation between hours growth and price growth should be weaker than the correlation between expected output growth and expected price growth.

Consider first a shock that becomes known at $t$ and which raises $x_{\tau}$ for all $\tau \geq t$ by the same amount. Equation (11) implies that, assuming the money stock does not respond, prices at $t$ fall by $(1-\alpha)$ times the amount of the shock. Because output is proportional to real money balances, this implies that, output rises by $(1-\alpha)$ times the amount of the shock. Hours worked, on the other hand, must fall at $t$ since output would rise by the full amount of the shock if man-hours remained constant. ${ }^{16}$ After the shock, since $x$ and $m$ are not expected to change, the expected changes in hours are proportional to the expected changes in output.

Thus, the presence of this type of technology shock does not alter the implication that revisions in price growth should be related in the same way to revisions in output growth as to revisions in hours growth. But, such a shock has an instantaneous effect on prices and

\footnotetext{
${ }^{15}$ Part of the reason why output-price and hours-price correlations differ in practice may be attributable to capital accumulation. In this crude model, this too is captured by variations in $x$. However, the model neglects the endogeneity of these variations in $x$. For a model that takes this into account, see Hairault and Portier (1992).

${ }^{16}$ In the standard real business cycle model, a positive technology shock raises output and hours. In the current model, hours would stay constant even if prices were flexible because the model lacks a positive response of labor supply. Sticky prices then ensure that output rises less than it would with flexible prices so that hours fall.
} 
hours of the same sign. It tends to make the correlation between hours and price innovations positive, while it tends to make the correlation between output and price innovations negative. Assuming there are also monetary shocks of the sort considered earlier, one can say only that these movements in $x_{t}$ lead price and hours innovations to be more positively correlated than price and output innovations. As we shall see, this prediction of the theory is upheld.

Now consider a similar sort of permanent shock to productivity but imagine that it becomes know earlier. Thus, the shock at $t$ has no effect on $x_{\tau}$ for $\tau$ between $t$ and $t+\ell$ but raises $x_{\tau}$ for all $\tau$ greater than $t+\ell$. Because prices are sticky and forward looking, (11) implies that prices start falling immediately, though their fall at $t$ will be small is $\ell$ is sufficiently large. This means that output and hours rise at $t$. After $t$, the shock implies that prices will continue to fall and output will continue to grow. Hours, on the other hand, can be expected to fall at $t+e l l$ when the economy finally does become more productive. Indeed, since hours rise at $t$, they must be expected to decline between $t$ and $t+\infty$. Since prices can also be expected to decline, the existence of this shock (always accompanied by a monetary authority that does not respond) weakens the negative correlation between revisions in hours growth and revisions in price growth. Thus, the existence of this shock would imply that the correlation between revisions in output growth and revisions in price growth should be stronger (and more negative) than the corresponding correlation involving revisions in hours growth.

I consider the relationship between man-hours and inflation in Table 3. The first row of this table shows that the standard deviation of the innovation in hours is about half as large as the standard deviation of the innovation in output. This is quite consistent with the fact stressed in Kydland and Prescott (1982) that hours move less than output. The second row shows that the innovation in hours is extremely highly correlated with the innovation in output. This is inconsistent with a large role for "random walk" technology shocks in the sticky price model of section 1 since that model leads output and hours to move in opposite directions in response to such shocks. However, since the two series are 
not perfectly correlated, such shocks can play at least a modest role.

The next set of rows displays many of the correlations displayed in Tables 1 except that I use revisions in the growth of man-hours as opposed to revisions in the growth of output. Recall that hours are stationary so that revisions in the growth of hours between $t$ and $t+\infty$ are simply the negative of the innovation in the level of hours at $t$ so the table also shows some aspects of this innovation. Consistent with the existence of some shocks to technology at $t$ that become known at $t$, there is a stronger positive correlation between the hours and the price innovation at $t$ than between the output and price innovation. This can be seen by comparing the entries in the third row of Table 3 to those in the third row of Table 1. On the other hand, the hours innovation (or the revision in hours growth over the infinite horizon) is generally more weakly associated with the price revision over the infinite horizon than is the output revision. For example, the correlation between $\widetilde{\Delta h}^{\infty}$ and $\widetilde{\Delta p}^{\infty}$ is only -.57 when both the interests rate and the monetary base are included in the VAR while, in this system, the correlation between $\widetilde{\Delta y}^{\infty}$ and $\widetilde{\Delta P}^{\infty}$ is $-.712 .{ }^{17}$ This suggests some role for shocks to technology at $t+\ell$ that become known at $t$.

Perhaps a more direct method for studying whether the expected growth in hours or the expected growth in output is more closely related to expected price movements is to run regressions that explain revisions in predicted price movements with both the revision of output growth and the revision of hours growth. Regressions of this sort are reported in Table 4. For each specification, I construct the sample path of $\widetilde{\Delta p}^{k}, \overline{\Delta y}^{k}$ and $\widetilde{\Delta h}^{k}$ that follows from the point estimates of the estimated VAR. Then, I run regression of the sample path of $\widetilde{\Delta p}^{k}$ on the other two revisions. The resulting estimates and standard errors are reported for $k$ equal to 10 quarters and to infinity.

In the case where the VAR includes the labor share, adding the revision of hours growth to a regression that already includes the output revision has essentially no effect. The coefficient on the hours variable is small and statistically insignificant while the coefficients

\footnotetext{
${ }^{17}$ Only when the VAR includes the labor share are hours revisions more closely associated with expected inflation.
} 
on the output variable are very similar to those reported below in Table 5 . Thus, in this specification, any correlation of the revision in hours growth with inflation growth is due to the correlation of expected output growth with expected hours growth. In other words, any movement in hours growth that is not correlated with output growth has no important effect on inflation. On the other hand, the regression results say that revisions in output growth have the same effect on inflation whether or not they are associated with expected changes in hours from $t$ to infinity.

On the other hand, revisions in hours growth do have an independent effect on inflation in the other specifications. But, this effect is of the opposite sign than the usual "Phillips" curve effect. Such a Phillips curve effect was present in Table 3 where positive revisions in hours growth (or negative hours innovations) where negatively correlated with revisions in prices. This meant that a tight current labor market (a positive innovation in hours) was associated with a positive revision in expected inflation. But, in the regressions of Table 4 we see the opposite. Positive revisions in hours growth (i.e.,negative innovations in hours) are positively related to inflation holding constant the revision in output growth. On the other hand, positive revisions in output growth remain negatively correlated with revisions in prices, even holding constant revisions in hours growth.

The fact that expected output growth maintains its negative effect on price growth even in the presence of the expected hours growth variable is consistent with the model of section 1 as long as there are variations in the expected growth of $x$. On the other hand, the independent positive effect of expected hours growth is not so easy to rationalize. One possibility, whose full exploration must await further work, is that the money supply does, after all, react to certain technology shocks and that the difference between expected hours growth and expected hours growth is a proxy for these shocks.

In this section I have considered only the relationship between man-hours and prices as opposed to the more conventional relationship with unemployment. As suggested earlier I have done this mainly because man-hours are more closely associated with output growth. However, for completeness, the bottom row of Table 3 presents correlations of price revisions 
with unemployment revisions. To obtain these I fit a VAR that includes the detrended unemployment rate rather than detrended man-hours. This VAR can be used to obtain revisions in the growth rate of unemployment which, for the infinite horizon are once again equal to (minus) the unemployment innovation. The last row presents the correlation of this revisions over the infinite horizon with the corresponding revision for price growth. Except in the case where the VAR includes M2, these correlations are quite a bit smaller than the correlations using man-hours. While the unemployment correlation exceeds the manhours correlation in the case of M2, its absolute size is quite small (.283); the VAR with M2 just happens to generate unusually low correlation of man-hours and price revisions. Thus, the use of unemployment, rather than man-hours, does not seem to generate stronger relationships with inflation.

\section{The Pattern of Monetary Policy}

So far, I have considered the evidence only in terms of the model of section 1 . That model is of course very restrictive, so that I have only looked for a very broad correspondence between the model's predictions and the comovements of output, prices and hours. In this section I discuss somewhat more broadly the implications of the empirical findings. I start by reinterpreting the earlier results in light of a variant of the model of section 1 that has endogenous monetary policy and flexible prices. Then, I turn to a more general discussion of what the findings imply about the pattern of monetary policy.

It should be clear that the model of section 1 is consistent with any correlation of price and output innovations even if $x_{t}$ is the only source of output fluctuations and prices are flexible. As pointed out by King and Plosser (1984), all that is needed is that $m_{t}$ respond immediately to changes in $x_{t}$. To see this, note that, ignoring the effects of the inflation tax, flexible prices imply that hours are constant. The result is that $y_{t}$ is, up to a constant, equal to $x_{t}$ while $p_{t}$ is, again up to a constant, equal to $m_{t}-x_{t}$. Now suppose that $x_{t}$ follows a random walk. Then, positive innovations in $x_{t}$ will lead prices to rise together with output as long as a one unit increase in $x_{t}$ raises $m_{t}$ by more than one unit. This leaves the 
question of why forecastable movements in output are negatively correlated with forecastable movements in prices.

Obviously, the neglect of capital accumulation implies that, in this model, there are no forecastable movements in output if $x_{t}$ follows a random walk. ${ }^{18}$ But, there can be forecastable output movements if information is revealed at $t$ about movements in $x$ at $t+\ell$ where $\ell$ is strictly positive. If it becomes known at $t$ that $x_{t+\ell}$ will rise, agents at $t$ will forecast that output will rise between $t$ and $t+\ell$. For prices to be forecasted to decline over this period, it must be the case that $m$ will not rise at $t+\ell$ by as much as $x$.

Thus for output and price innovations to be positively correlated while predictable price movements are negatively correlated with predictable output movements, there must be a difference in the way money responds to unanticipated changes in $x$ and the way it responds to movements in $x$ that are anticipated. This may explain why King and Watson (1993) had difficulty explaining the behavior of the price level in a model driven exclusively by technology shocks even after allowing for a fairly elaborate monetary feedback rule. The difficulty arises because their feedback rule may not distinguish sufficiently between predictable and unpredictable movements in $x .{ }^{19}$ What is left for further research is to analyze whether it makes sense for money to respond differently to the two types of movements in $x$. What would seem to make this a particularly difficult task is that, as we saw, positive innovations in output are associated with expected declines in output. If this is attributed to temporary increases in $x_{t}$, one would have to explain why $m$ rises dramatically when $x_{t}$ rises unexpectedly but does not decline as $x$ itself falls back towards its normal value.

It should be apparent from this discussion that the relationship between prices and output is as informative about the way the money stock evolves in response to shocks as it is about the validity of particular models of price and output determination. In other words, one can reconcile these data with different price setting models as long as one is willing to entertain

\footnotetext{
${ }^{18}$ Rotemberg and Woodford (1994) argue that a random walk in technology within a richer neoclassical model also leads to forecastable output movements that are much smaller than the observed ones.

${ }^{19}$ Similarly, Yun's (1994) rejection of a flexible price model with a monetary feedback rule is probably due to the fact that he only allows money to respond to unanticipated, permanent changes in technology.
} 
different models for the determination of the money stock. That is not to say that the price-output correlations contain no information about price determination in aggregative models. What makes the sticky price model of section 1 attractive as an explanation of the price-output correlations is that it involves a money supply rule that is simple, plausible, and not too widely at variance with the observed movements in monetary aggregates.

This raises the question of whether the price-output correlations embody information about the money supply rule that can be described in general terms. In the rest of this section, I will attempt to do so. My inferences will be based on the validity of (5), but this is not very restrictive. It does not require a constant velocity of official monetary aggregates since the model is consistent with the existence of a second monetary asset as in (20) and with a varying share of the two assets as in (22).

To make relatively general statements about monetary policy, I will compare the behavior of U.S. data to what one would predict if the monetary authority followed a simple policy. According to this policy, the central bank would not allow $m$ to change from $t+1$ onwards in response to any information that is revealed at $t$. In other words, I will consider monetary rules where $m_{t}$ can change in response to innovations at $t$ but where these period $t$ innovations are not systematically related to further changes in the effective money supply. Note that such a monetary rule embodies the assumption that the government is expected to offset predictable changes in $V^{\circ}$, the velocity of the official aggregate in (22), with changes in $M^{\circ}$. On the other hand, the rule does not require that the monetary authority be able to respond at $t$ to innovations in $V_{t}^{o}$ since it allows all period $t$ innovations to affect $m_{t}$. Finally, note that the existence of lags in the effects of changes in money on output poses no problem for implementing this rule since $M^{o}$ needs only to chnage in response to predictable movements in $V^{o}$.

Given this monetary policy rule, the cash in advance constraint (5) implies that forecastable changes in $y$ from $t$ onwards must typically be accompanied by a forecastable change of the same magnitude and the opposite direction in $p$. In other words, it is a rule where nominal GDP is not expected to change. This is at least consistent with the negative corre- 
lation between forecastable price and output movements over long horizons that I presented in Table 1. Further information on the extent to which the Federal Reserve obeys this rule and on the direction in which it departs from it can be obtained from two sources. The first is the study of the magnitude of the expected price change that is associated with a given expected output change. The second is the observation of expected changes in the monetary aggregates themselves.

If the monetary rule were followed exactly and (5) held without error, there would be a deterministic relation between expected price and expected output changes. As above, I will suppose that the rule is not exact: any given expected output change is sometimes associated with a slight increase in $m$ and sometimes associated with a slight decrease. I assume further that these slight increases or decreases in $m$ have a negligible effect on the expected change in output itself. Such an effect would be entirely absent if output depended only on technological opportunities. It would also be absent in the Lucas (1973) model where predicted output growth is independent of predicted monetary policy. But, even in a model such as that of section 1 , where predictable monetary policy has real effects, the effect on current output (and thus on predictable growth in output) of an increase in $m$ in the far future is negligible. On the other hand, such an increase has a significant effect on predicted price growth. As I argued earlier, this suggests that for long horizons the error in the regression of revisions in expected price growth on revisions in output growth is mostly associated with the price revisions.

Table 5 displays these regressions as well as similar regressions for the one quarter horizon. The regression coefficients suggest that the actual policy of the Federal Reserve differs dramatically from the policy of eliminating predictable movements in $m$ (and thus in nominal GDP). Consider in particular the first row of this table which reproduces the seventh row of Table 1. This indicates that, when expected output growth from $t$ to infinity exceeds average output growth by one percent, expected price growth falls short of average price growth by more than one percent. All the coefficients have absolute values above 1.19 and the sampling variance in $A$ is sufficiently small that, except in one case, one can reject at 
conventional significance levels the hypothesis that these regression coefficients are smaller than or equal to one in absolute value. Thus, rather than keeping $m$ constant in the face of a predictable increase in output, the monetary authority appears to let $m$ fall. This means that the policy exacerbates the volatility in expected price growth. In other words, expected price growth is more variable with the Federal Reserve's actual policy than it would be with the policy of keeping constant the expected growth in nominal GDP.

I also ran regressions of the revisions in price growth at various horizons on the revision in output growth from $t$ to infinity. The resulting coefficients are all negative, meaning that prices are expected to fall over all horizons when output is expected to rise from $t$ to infinity. Evidence that the movement in prices is in fact monotone can be gleaned from the fact that the coefficients on these last three regressions rise in absolute value as the horizon lengthens. I thus conclude that, relative to the baseline case, monetary policy contributes to unusually high inflation whenever output is expected to decline between $t$ and infinity.

There are several interpretations for this finding. The first is that recessions are periods where the Fed is trying to reduce long run inflation and that the Fed continues to clamp down even after the economy is in a recession. this is very much in the spirit of the earlier analysis in which monetary instability caused all output fluctuations and the existence of a positive $a$ in (12) implied that a recessionary shock would be followed by further tightening. The second assigns no role to the Fed in creating the recessions. Instead, the result may simply be due to a Fed reaction to recessions caused by other forces. These recessions are followed by recoveries where output is expected to grow fast. This fast growth in output may scare the Fed into believing that a tightening is needed to avoid overheating.

So far, I have shown that monetary policy leads to atypically large expected increases in nominal GDP when real GDP is expected to fall. Thus expected falls in real GDP are associated with a more expansionary policy than in the baseline case. I now ask whether these expansionary policies are associated with actual increases in official monetary aggregates or whether they are simply due to increases in the aggregates' velocities. For this purpose, I study the association between revisions in money growth and output growth revisions. A 
negative association would provide evidence that the money stock itself is adjusted in a way that destabilizes expected inflation. It would imply that money growth is particularly large, so that inflation must rise, when output growth is small. But, these are precisely the periods where inflation would already be relatively large even if the government followed the rule of stabilizing money growth.

Table 6 shows correlations between revisions in the grow th of various monetary aggregates and revisions in output growth. It also displays regression coefficients relating money growth revisions to output growth revisions. These are shown only for those specifications including a monetary aggregate. Moreover, the money stock revision I consider in each column relates to the monetary aggregate that is present in that column's specification. Thus, the last column shows the behavior of revisions in the monetary base that are computed from the VAR that includes both the monetary base and the federal funds rate.

We see from the first row in this table that, for all monetary aggregates that I study, money growth revisions from $t$ to infinity are indeed negatively correlated with output revisions from $t$ to infinity. This is consistent with the fact that a one percent positive output revision is associated with a price declines larger than one percent. In fact, the regressions in the second row indicate that the size of expected declines in money when output growth is revised upwards is quite substantial. Finally, the third row of the table shows that this decline in money that is associated with long term upwards revisions in output is already expected to take place one quarter after output growth is revised.

One can learn about expected movements in velocity by comparing the coefficient of the regression that relates the money revision to the output revisions and the coefficient of the regression that relates the price revision to the output revision. If the former is equal to the latter minus one, expected velocity changes are unrelated to expected output changes. In the case of the monetary base and the CE aggregate, the coefficients in the regression explaining the revision in money growth from $t$ to infinity are so large in absolute value that the growth in velocity is revised upwards when there is an upwards revision in output growth, even though nominal GDP is expected to decline. On the other hand, M1 and M2 
velocity growth is revised downwards when output growth is revised upwards.

The broad conclusion of this section is that monetary policy is tight when output can be expected to expand and loose when it can be expected to contract. Since periods where output can be expected to expand generally correspond to recessions, these findings do not suggest that monetary policy contributes to the ending of recessions. The issue is then how these findings can be reconciled with those of Romer and Romer (1994) who conclude that recessions would have been far worse if the monetary authority had not intervened. In fact, the empirical findings of this paper are largely consistent with those of Romer and Romer (1994). They focus mostly on interest rates as indicators of monetary policy and they show that the Federal Reserve intentionally lets interest rates fall as the economy declines from peaks to troughs. But, at the same time, Romer and Romer (1994) report that monetary policy turns tight immediately after the trough (as the economy expands back towards its steady state).

This tightening of policy during periods when output is expected to rise is exactly what I find. I also find evidence that is consistent with theirs for shorter horizons. In the VAR that includes the federal funds rate (and is thus most comparable to their analysis), revisions in output growth over the next quarter are strongly positively associated with revisions in the growth of the interest rate over that quarter. The correlation between these two revisions is .561 (with a standard error induced by the sampling variance of $A$ that is equal to .026 ). At the onset of recessions, there is a negative innovation in output and output is expected to fall further in the next quarter. ${ }^{20}$ These downwards revisions in output growth over the next quarter are, just as Romer and Romer (1994) suggest, associated with declines in interest rates.

Romer and Romer (1994) argue that these declines in interest rates represent a loosening of monetary policy and that they prevent the recession from becoming as deep as it would otherwise be. Whether one agrees with this or not, my results shows that this loosening of

\footnotetext{
${ }^{20}$ As I discussed earlier output innovations are negatively correlated with revisions of output growth from $t$ to infinity, but they are positively associated with revisions of output growth from $t$ to $t+1$.
} 
policy does not obviate the need for price adjustments. The entire package of monetary policy, including the contractionary policy after troughs, is such that substantial price declines appear to be needed to "end" recessions.

In U.S. data, recessions end relatively quickly. As Rotemberg and Woodford (1994) show, most of the output movements that are expected to take place eventually are expected to take place within the next 10 quarters. This suggests that the needed price adjustments occur relatively quickly as well. Thus, while price rigidity may cause recessions, it does not cause protracted ones.

\section{Conclusions}

The main message of this paper is that a relatively simple sticky price model that attributes output volatility to monetary disturbances can easily be reconciled with the three most important features of price and output co-movements. The first of these is that unexpected movements in output are positively associated with unexpected price movements. The second is that revisions in output growth from $t$ to infinity are negatively associated with the corresponding revisions of price growth (so that prices and output are negatively correlated once they are detrended using the Beveridge-Nelson method). The third is that revisions in output growth over the next quarter are positively associated with the corresponding price revisions.

These results do not rule out that the volatility of output has other, real, causes. But, such a real interpretation does seem to require an unusual set of responses of money to real shocks. In particular unexpected positive movements in output must be associated with substantial increases in money whereas predictable positive growth in output from $t$ to infinity must be associated with a predictable decline in money from $t$ to infinity.

The results also allow one to deduce some general characteristics of the way in which the Federal Reserve sets money in the aftermath of shocks, whether these be monetary or not. Shocks that raise output temporarily lead to expectations of output declines. If the central bank stabilized the expected rate of growth of nominal GDP, these expected output 
declines would be associated with expected price increases of the same magnitude. Instead, I find that expected output declines are associated with expected price increases that are larger in absolute value than the output declines. This exaggerated response of expected price growth suggests that monetary policy is expansionary precisely when output growth can be expected to be small. Such a policy implies a larger volatility of expected inflation than would result from a policy that tried to stabilize the expected growth in nominal GDP. This characteristic of the way money is set may appear undesirable. In particular, suppose that the economy finds itself in a recession so that expected output growth from $t$ to infinity is large. If one felt that the recession is protracted only because prices fail to fall, then a policy of reducing money growth in this instance would seem counterproductive. On the other hand, it must be kept in mind that this policy also affects the way that prices react to shocks. In particular, the forward-looking sticky price model presented in this paper implies that temporary negative shocks are associated with larger instantaneous price declines if the recovery from the shock can be expected to be accompanied by reductions in money. Thus, the policy of accompanying the recovery with declines in money may reduce the recessionary impact of the original negative shock. 


\section{References}

Blanchard, Olivier J: "A Traditional Interpretation of Macroeconomic Fluctuations," American Economic Review, 79, December 1989, 1146-1164.

—-: "Movements in the Equity Premium," Brookings Papers on Economic Activity, 1993:2, 75-118.

Blanchard, Olivier J. and Danny Quah:"The Dynamic Effects of Aggregate Supply and Demand Disturbances," American Economic Review, 79, September 1989, 655-73.

Calvo, Guillermo: "Staggered Prices in a Utility-Maximizing Framework," Journal of Monetary Economics, 12, 1983, 383-98.

Caballero, Ricardo J. and Eduardo M.R.A. Engel:"Price Rigidities, Asymmetries, and Output Fluctuations," European Economic Review, 1992.

Caplin, Andrew and John Leahy:"Aggregation and Optimization with State Dependent Pricing," mimeo, 1992

Campbell, John Y,:"Does Saving Anticipate Declining Labor Income? An Alternative Test of the Permanent Income Hypothesis," Econometrica, 55, November 1987, 1249-73.

Chadha, Bankim and Eswar Prasad:"Are Prices Countercyclical? Evidence from the G-7", mimeo, 1994.

Christiano, Lawrence, J and Martin Eichenbaum: "Liquidity Effects, and the Monetary Transmission Mechanism," NBER Working paper 4129, 1992.

Cochrane, John H. and Argia Sbordone:"Multivariate Estimates of the Permanent Components of GNP and Stock Prices," Journal of Economic Dynamics and Control, 12, June/September 1988, 255-96.

Cooley, Thomas F. and Gary D. Hansen:"The Inflation Tax in a Real Business Cycle Model," American Economic Review, 79, September 1989, 733-48.

Cooley, Thomas F. and Lee E. Ohanian:"The Cyclical Behavior of Prices," Journal of Monetary Economics, 28, August 1991, 25-60.

Evans, George: "Output and Unemployment Dynamics in the United States: 1950-1985," Journal of Applied Econometrics, 4, July-September 1989, 213-37. 
Fischer, Stanley: "Long Term Contracts, rational expectations, and the Optimal Money Supply Rule," Journal of Political Economy, 85, 1977, 163-190.

Gordon, Robert J,: "The Recent acceleration of Inflation and its Lessons for the Future," Brookings Papers on Economic Activity, 1970:1, 8-41.

- "A Consistent Characterization of a Near Century of Price Behavior," American Economic Review, May 1980, 70, 243-249.

Hairault, Jean-Olivier and Franck Portier: "Money, New-Keynesian Macroeconomics and the Business Cycle," European Economic Review, forthcoming.

Jeanne, Olivier:"Nominal Rigidities and the Liquidity Effect," mimeo, Ecole Nationale des Ponts et Chausses, 1994.

Kashyap, Anil K.: "Sticky Prices: New Evidence from Retail Catalogues," Review of Economic Studies, 1994.

King, Robert G.: "Money and Business Cycles," mimeo, 1992.

King, Robert G. and Charles Plosser:"Money, Interest and Credit in a Real Business Cycle," American Economic Review, 74, 1984, 363-80.

King, Robert G. and Mark W. Watson: "Money, Interest Rates, Prices and the Business Cycle," manuscript presented at the October 1993 NBER Economic Fluctuations meeting.

- and - :The Post-War U.S. Phillips Curve: A Revisionist Econometric History," Carnegie-Rochester Conference on Public Policy, 1994, forthcoming.

Kydland, Finn and Edward Prescott:"Business Cycles: Real Facts and a Monetary Myth," Federal reserve Bank of Minneapolis Quarterly Review, Spring 1990.

Lucas, Robert E. Jr.:"Some International Evidence on Output-Inflation Tradeoffs," American Economic Review, 63, 1973, 326-334.

Lucas, Robert E. Jr. and Nancy L. Stokey:"Money and Interest in a Cash-in-Advance Economy," Econometrica, 55, 1987, 491-513.

Perry, George L.: "Changing Labor Markets and Inflation," Brookings Papers on Economic Activity, 1970:3, 411-41.

Romer, Christina and David Romer, "What Ends Recessions," NBER Macroeconomics Annual 1994 (forthcoming) 
Rotemberg, Julio J.: "Sticky Prices in the United States," Journal of Political Economy, $1982,90,1187-211$.

Rotemberg, Julio J., John C. Driscoll and James M. Poterba: "Money, Output and Prices: Evidence from a New Monetary Aggregate," Journal of Business and Economic Statistics, 1994, forthcoming.

Rotemberg, Julio J. and Michael Woodford: "Is the Business Cycle a Necessary Consequence of Stochastic Growth?", 1994, mimeo.

Sims, Christopher A.: "Are Policy models Usable for Policy Analysis?" Quarterly Review, Federal Reserve bank of Minneapolis, Winter 1986, 2-16.

Taylor, John B.:"Aggregate Dynamics and Staggered Contracts," Journal of Political Economy, 88, 1980, 1-23.

Yun, Tack: "Nominal Price Rigidity, Money Supply Endogeneity, and Business Cycles," mimeo, University of Chicago, 1994

Woodford, Michael:"Stationary Sunspot Equilibria: The Case of Small Fluctuations around a Deterministic Steady State," unpublished, University of Chicago, 1986. 


\section{Appendix \\ A Variant where Increases in Money Lower Interest Rates}

Suppose once again that there are two assets that can be used for transactions. In particular, transactions are facilitated not just by the use of official money $M_{t}^{o}$ but also by the use of another asset $M_{t}^{A}$. But, now, I do not impose any restriction on the interest rate paid by this asset. Rather, I restrict its total supply in real terms. I assume simply that the asset is issued by the government and that the government keeps fixed the real supply $M_{t}^{A} / P_{t-1} .{ }^{21}$ On the other hand, I will let the government vary the real supply of $M_{t}^{o}$ by varying $T_{t}$, as before.

To ensure that both assets are demanded even though their relative rate of return varies, I assume that (5) is now given by

$$
P_{t} C_{t}^{j} \leq M_{t}^{j} \equiv\left(M_{t}^{o j}\right)^{\lambda}\left(M_{t}^{A j}\right)^{1-\lambda}
$$

whereas, assuming (31) holds as an equality, the household intertemporal budget constraint (6) becomes

$$
M_{t+1}^{o j}+\frac{M_{t+1}^{A j}}{1+i_{t}}=P_{t}^{j} X_{t} F\left(H_{t}^{j}\right)+T_{t+1}^{j}
$$

In this equation, $i_{t}$ represents the nominal rate of interest on the alternative asset $M_{t}^{A}$. This interpretation is natural because (31) requires that $M_{i}^{A}$ be measured in the same units (dollars) as $M_{t}^{o}$ and $P_{t} C_{t}$. Thus $\frac{M_{t+1}^{A j}}{1+i_{t}}$ represents the dollar cost at $t$ of obtaining one dollar of $M_{t+1}^{A j}$.

For any given choice of hours worked at $t$, individuals want to choose their portfolio to maximize their consumption at $t+1$. I assume they make this portfolio choice after receiving the transfer $T_{t+1}^{j}$ as well as after setting their period $t$ price, which determines their employment at $t$. Thus

$$
M_{t+1}^{A j}=\frac{1-\lambda}{\lambda}\left(1+i_{t}\right) M_{t+1}^{o j}
$$

Dividing through by $P_{t}$, and remembering that $M_{t}^{A} / P_{t-1}$ is constant, we have

$$
\left(1+i_{t}\right) \frac{M_{t+1}^{o j}}{P_{t}}=\text { constant }
$$

Using (31), (32) and (33), it follows that utility in this two asset model can be written as

$$
\begin{aligned}
U^{i}=E_{t} \sum_{k} \beta^{k}\left\{\lambda^{\lambda}\left[\left(1+i_{t+k-1}\right)(1-\lambda)\right]^{1-\lambda}\left[\frac{P_{t+k-1}^{j}}{P_{t+k}} \frac{M_{t+k-1}}{P_{t+k-1}} d\left(\frac{P_{t+k-1}^{j}}{P_{t+k-1}}\right)+\frac{T_{t+k}^{j}}{P_{t+k}}\right]-\right. \\
v\left(F^{-1}\left(\frac{M_{t+k}}{P_{t+k} X_{t+k}} d\left(\frac{P_{t+k}^{j}}{P_{t+k}}\right)\right)\right)-\frac{c X_{t}}{2}\left[\log \left(P_{t+k}^{j}\right)-\log \left(P_{t+k-1}^{j}\right)\right]^{2355)}
\end{aligned}
$$

\footnotetext{
${ }^{21}$ Alternatively one could assume that the asset is issued privately and that its supply is fixed due to regulations or to the existence of a limited stock of assets that can credibly be used as collateral. The incorporation of private issue would, however, complicate the issuers budget constraints. The reason I fixed $M_{t}^{A} / P_{t-1}$, rather than $M_{t}^{A} / P_{t}$, is that $P_{t}$ is not known at $t-1$ when $M_{t}^{A}$ is issued. But the analysis would remain unchanged if, say, what was assumed fixed was the expectation at $t-1$ of $M_{t}^{A} / P_{t}$.
} 
This equation is very similar to (8) and, while the first order condition differs from (9) in that it includes the interest rate, the qualitative properties of the model remain very similar. An increase in $M_{t+1}^{o}$, financed by an increase in $T_{t}$, raises $P_{t+1}$ but raises output at $t+1$ as well. Since this transfer must take place before people pick the composition of their portfolio, (34) implies that the interest rate between $t$ and $t+1$ falls, the model has a "liquidity effect". The nominal interest rate on bonds falls because, with sticky prices, the government is increasing the real supply of the zero interest asset it provides. But, people are only willing to hold this increased amount of the barren asset if the interest rate on competing assets falls. 
Figure 1

Predictable Output Growth

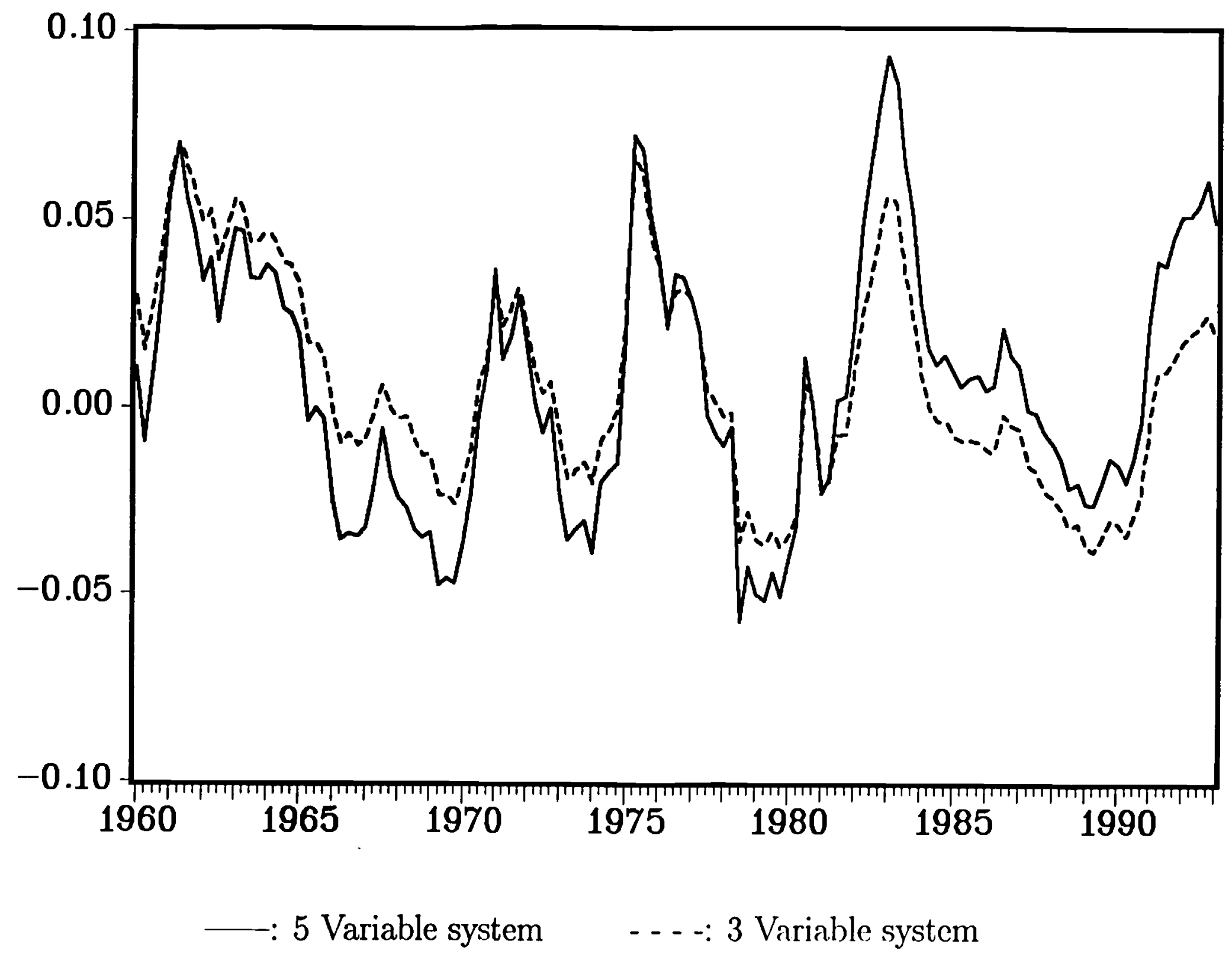


Figure 2

Predictable Output and Price Growth

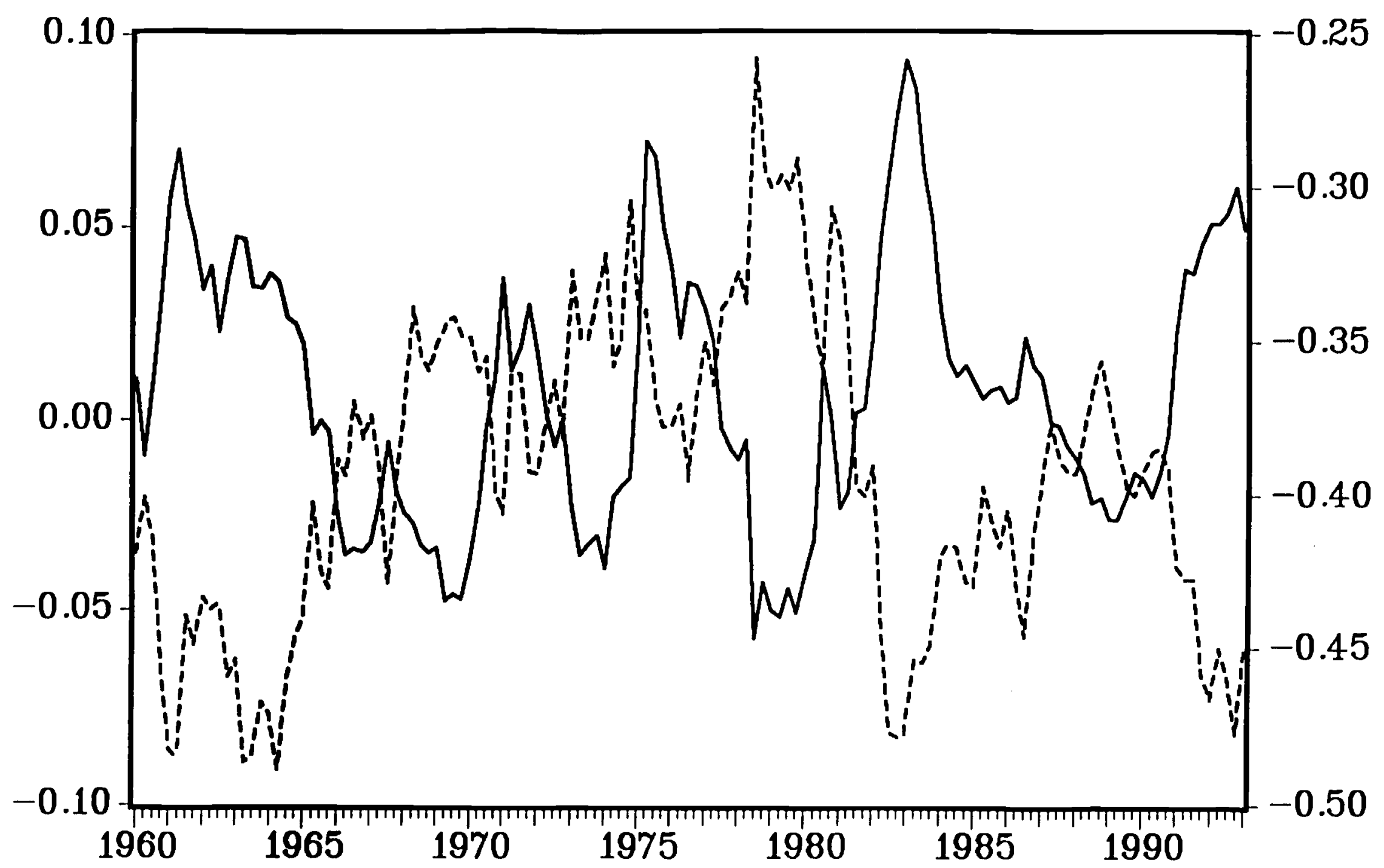

$\longrightarrow: \widehat{\Delta y}_{t}^{\infty} \quad \cdots-: \widehat{\Delta p}_{t}^{\infty}$ 
Figure 3

Scatterplot of Revisions in Price and Output Growth

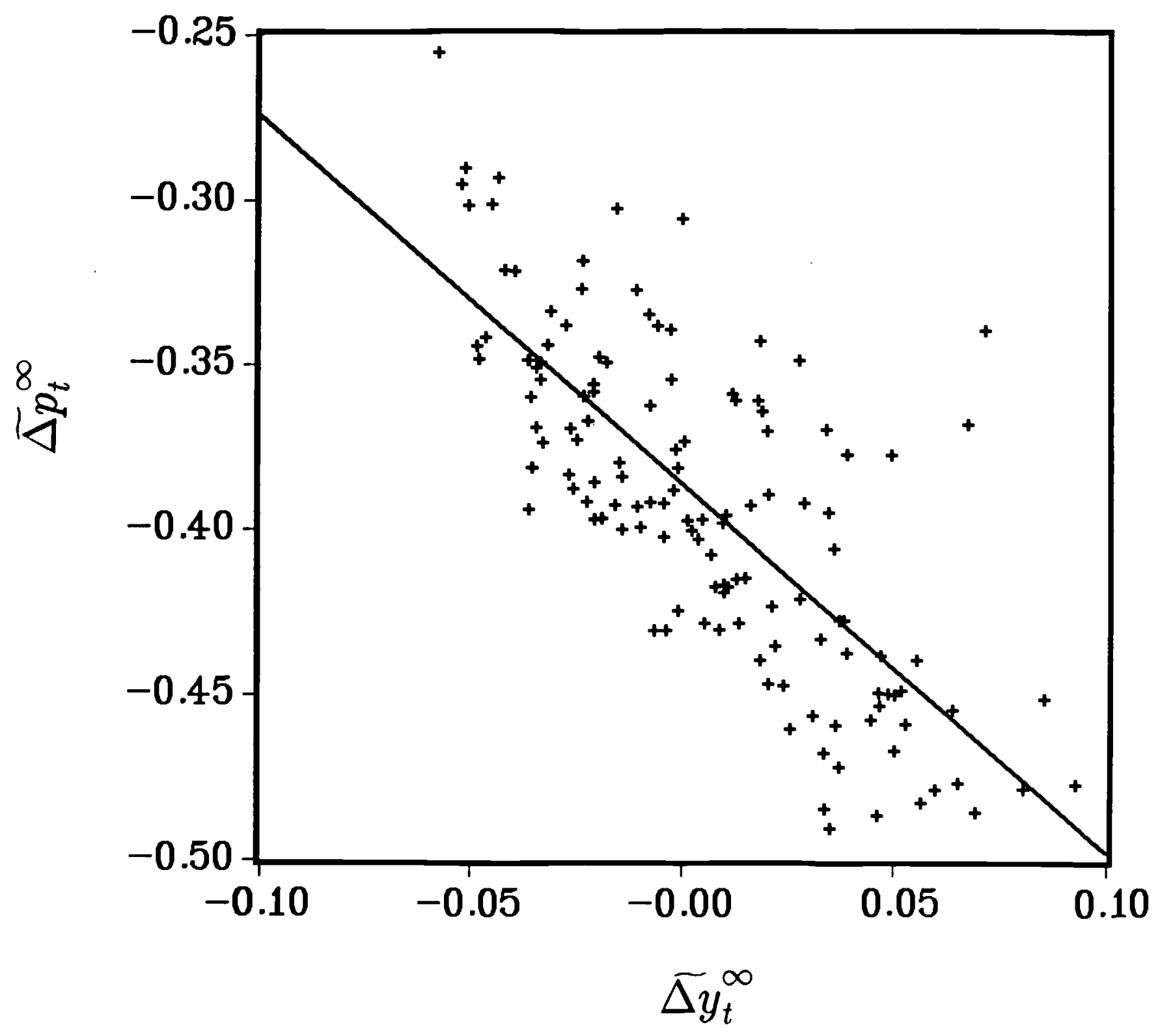


Table 1

The properties of inflation and output changes:

Innovations versus revisions in predicted changes.

\begin{tabular}{|c|c|c|c|c|c|c|c|}
\hline Included vars.: & $i$ & $\Delta M_{b}$ & $\Delta M_{1}$ & $\Delta M_{2}$ & $\Delta M_{C}$ & $s_{H}$ & $i \& \Delta M_{b}$ \\
\hline S.D. $\epsilon^{y}$ & $\begin{array}{c}0.0077 \\
6 \mathrm{E}-5\end{array}$ & $\begin{array}{c}0.0081 \\
5 \mathrm{E}-5\end{array}$ & $\begin{array}{c}0.0081 \\
6 \mathrm{E}-5\end{array}$ & $\begin{array}{c}0.0080 \\
6 \mathrm{E}-5\end{array}$ & $\begin{array}{c}0.0083 \\
6 \mathrm{E}-5\end{array}$ & $\begin{array}{c}0.0081 \\
6 \mathrm{E}-5\end{array}$ & $\begin{array}{c}0.0077 \\
6 \mathrm{E}-5\end{array}$ \\
\hline S.D. $\epsilon^{p}$ & $\begin{array}{c}0.0036 \\
5 \mathrm{E}-5\end{array}$ & $\begin{array}{c}0.0036 \\
5 \mathrm{E}-5\end{array}$ & $\begin{array}{c}0.0036 \\
5 \mathrm{E}-5\end{array}$ & $\begin{array}{c}0.0036 \\
5 \mathrm{E}-5\end{array}$ & $\begin{array}{c}0.0038 \\
5 \mathrm{E}-5\end{array}$ & $\begin{array}{c}0.0034 \\
5 \mathrm{E}-5\end{array}$ & $\begin{array}{c}0.0035 \\
5 \mathrm{E}-5\end{array}$ \\
\hline $\operatorname{Corr}\left(\epsilon^{y}, \epsilon^{p}\right)$ & $\begin{array}{l}0.075 \\
0.016\end{array}$ & $\begin{array}{l}0.083 \\
0.016\end{array}$ & $\begin{array}{l}0.076 \\
0.016\end{array}$ & $\begin{array}{l}0.058 \\
0.016\end{array}$ & $\begin{array}{l}0.071 \\
0.016\end{array}$ & $\begin{array}{l}0.150 \\
0.017\end{array}$ & $\begin{array}{l}0.074 \\
0.017\end{array}$ \\
\hline S.D. $\widetilde{\Delta y}^{\infty}$ & $\begin{array}{c}0.012 \\
4 \mathrm{E}-4\end{array}$ & $\begin{array}{l}0.012 \\
3 \mathrm{E}-4\end{array}$ & $\begin{array}{l}0.012 \\
3 \mathrm{E}-4\end{array}$ & $\begin{array}{l}0.012 \\
4 \mathrm{E}-4\end{array}$ & $\begin{array}{l}0.013 \\
3 \mathrm{E}-4\end{array}$ & $\begin{array}{l}0.012 \\
3 E-4\end{array}$ & $\begin{array}{l}0.012 \\
3 \mathrm{E}-4\end{array}$ \\
\hline S.D. $\widetilde{\Delta p}^{\infty}$ & $\begin{array}{l}0.021 \\
9 \mathrm{E}-4\end{array}$ & $\begin{array}{l}0.025 \\
9 \mathrm{E}-4\end{array}$ & $\begin{array}{l}0.025 \\
9 \mathrm{E}-4\end{array}$ & $\begin{array}{c}0.031 \\
1.5 \mathrm{E}-3\end{array}$ & $\begin{array}{l}0.025 \\
8 \mathrm{E}-4\end{array}$ & $\begin{array}{l}0.025 \\
8 \mathrm{E}-4\end{array}$ & $\begin{array}{c}0.024 \\
1 \mathrm{E}-3\end{array}$ \\
\hline $\operatorname{Corr}\left(\widetilde{\Delta y}^{\infty}, \widetilde{\Delta p}^{\infty}\right)$ & $\begin{array}{c}-0.648 \\
0.023\end{array}$ & $\begin{array}{c}-0.742 \\
0.015\end{array}$ & $\begin{array}{c}-0.748 \\
0.015\end{array}$ & $\begin{array}{c}-0.743 \\
0.017\end{array}$ & $\begin{array}{c}-0.787 \\
0.013\end{array}$ & $\begin{array}{c}-0.846 \\
0.011\end{array}$ & $\begin{array}{c}-0.712 \\
0.019\end{array}$ \\
\hline$\widetilde{\Delta p}^{\infty}$ on $\overline{\Delta y}^{\infty}$ & $\begin{array}{l}-1.19 \\
0.068\end{array}$ & $\begin{array}{c}-1.541 \\
0.060\end{array}$ & $\begin{array}{c}-1.475 \\
0.058\end{array}$ & $\begin{array}{c}-1.890 \\
0.092\end{array}$ & $\begin{array}{c}-1.500 \\
0.051\end{array}$ & $\begin{array}{c}-1.739 \\
0.053\end{array}$ & $\begin{array}{r}-1.377 \\
0.066\end{array}$ \\
\hline $\operatorname{Corr}\left(\widetilde{\Delta y}, \widetilde{\Delta p}^{1}\right)$ & $\begin{array}{l}0.320 \\
0.038\end{array}$ & $\begin{array}{l}0.364 \\
0.037\end{array}$ & $\begin{array}{l}0.297 \\
0.039\end{array}$ & $\begin{array}{l}0.116 \\
0.044\end{array}$ & $\begin{array}{l}0.322 \\
0.037\end{array}$ & $\begin{array}{l}0.396 \\
0.035\end{array}$ & $\begin{array}{l}0.321 \\
0.042\end{array}$ \\
\hline $\operatorname{Corr}\left(\widetilde{\Delta y}^{10}, \widetilde{\Delta p}^{10}\right)$ & $\begin{array}{c}-0.625 \\
0.018\end{array}$ & $\begin{array}{c}-0.763 \\
0.016\end{array}$ & $\begin{array}{c}-0.739 \\
0.016\end{array}$ & $\begin{array}{c}-0.435 \\
0.041\end{array}$ & $\begin{array}{c}-0.787 \\
0.013\end{array}$ & $\begin{array}{c}-0.908 \\
0.012\end{array}$ & $\begin{array}{c}-0.654 \\
0.033\end{array}$ \\
\hline $\operatorname{Corr}\left(\epsilon^{y}, \widetilde{\Delta y}^{\infty}\right)$ & $\begin{array}{c}-0.820 \\
0.019\end{array}$ & $\begin{array}{l}-0.781 \\
0.0197\end{array}$ & $\begin{array}{c}-0.826 \\
0.018\end{array}$ & $\begin{array}{c}-0.910 \\
0.023\end{array}$ & $\begin{array}{l}-0.792 \\
0.0190\end{array}$ & $\begin{array}{c}-0.828 \\
0.018\end{array}$ & $\begin{array}{c}-0.788 \\
0.01 .9\end{array}$ \\
\hline$\widetilde{\Delta y}^{\infty}$ on $\epsilon^{y}$ & $\begin{array}{c}-1.234 \\
0.047\end{array}$ & $\begin{array}{c}-1.180 \\
0.043\end{array}$ & $\begin{array}{c}-1.265 \\
0.043\end{array}$ & $\begin{array}{c}-1.407 \\
0.059\end{array}$ & $\begin{array}{c}-1.266 \\
0.042\end{array}$ & $\begin{array}{c}-1.274 \\
0.044\end{array}$ & $\begin{array}{c}-1.270 \\
0.047\end{array}$ \\
\hline $\operatorname{Corr}\left(\epsilon^{p}, \widetilde{\Delta p}\right)$ & $\begin{array}{l}0.358 \\
0.018\end{array}$ & $\begin{array}{l}0.291 \\
0.015\end{array}$ & $\begin{array}{l}0.310 \\
0.016\end{array}$ & $\begin{array}{l}0.212 \\
0.025\end{array}$ & $\begin{array}{l}0.351 \\
0.015\end{array}$ & $\begin{array}{l}0.184 \\
0.013\end{array}$ & $\begin{array}{l}0.314 \\
0.016\end{array}$ \\
\hline
\end{tabular}


Table 2

Correlation of Inflation and Output Changes

Subsample Stability of $\operatorname{Corr}\left(\widetilde{\Delta y}^{\infty}, \widetilde{\Delta p}^{\infty}\right)$

\begin{tabular}{|l|cc|}
\hline Included Vars.: & $60: 1-73: 4$ & $74: 1-93: 1$ \\
\cline { 2 - 3 }$\Delta$ & -0.718 & -0.640 \\
$\Delta M_{b}$ & -0.747 & -0.729 \\
$\Delta M_{1}$ & -0.698 & -0.770 \\
$\Delta M_{2}$ & -0.784 & -0.846 \\
$s_{H}$ & -0.856 & -0.844 \\
$i \& \Delta M_{b}$ & -0.757 & -0.663 \\
\hline
\end{tabular}


Table 3

Total Man-hours and Inflation

\begin{tabular}{|lccccccc|}
\hline Included vars.: & $i$ & $\Delta M_{b}$ & $\Delta M_{1}$ & $\Delta M_{2}$ & $\Delta M_{C}$ & $s_{H}$ & $i \& \Delta M_{b}$ \\
& & & & & & & \\
\hline S.D. $\epsilon^{h}$ & 0.0042 & 0.0043 & 0.0044 & 0.0037 & 0.0056 & 0.0041 & 0.0042 \\
& 0.0003 & 0.0003 & 0.0003 & 0.0003 & 0.0002 & 0.0003 & 0.0003 \\
$\operatorname{Corr}\left(\epsilon^{h}, \epsilon^{y}\right)$ & & & & & & & \\
& 0.968 & 0.943 & 0.965 & 0.592 & 0.747 & 0.987 & 0.943 \\
& 0.053 & 0.048 & 0.048 & 0.070 & 0.032 & 0.056 & 0.050 \\
$\operatorname{Corr}\left(\epsilon^{h}, \epsilon^{p}\right)$ & 0.148 & 0.166 & 0.143 & 0.085 & 0.201 & 0.323 & 0.167 \\
& 0.055 & 0.053 & 0.053 & 0.064 & 0.042 & 0.053 & 0.054 \\
$\operatorname{Corr}\left(\widetilde{\Delta h}^{1}, \widetilde{\Delta p}^{1}\right)$ & 0.581 & 0.584 & 0.582 & 0.425 & 0.606 & 0.816 & 0.546 \\
& 0.025 & 0.025 & 0.025 & 0.033 & 0.023 & 0.016 & 0.080 \\
$\operatorname{Corr}\left(\widetilde{\Delta h}^{10}, \widetilde{\Delta p}^{10}\right)$ & -0.398 & -1.006 & -0.720 & 0.247 & -0.798 & -0.786 & -0.429 \\
& 0.058 & 0.215 & 0.127 & 0.071 & 0.038 & 0.051 & 0.114 \\
$\operatorname{Corr}\left(\widetilde{\Delta h}^{\infty}, \widetilde{\Delta p}^{\infty}\right)$ & -0.535 & -0.612 & -0.622 & -0.006 & -0.699 & -0.969 & -0.570 \\
& 0.038 & 0.035 & 0.033 & 0.092 & 0.023 & 0.046 & 0.135 \\
$\operatorname{Corr}\left(\widetilde{\Delta u}^{\infty}, \widetilde{\Delta p}^{\infty}\right)$ & 0.330 & 0.280 & 0.295 & 0.283 & 0.534 & 0.598 & 0.360 \\
& 0.031 & 0.031 & 0.032 & 0.031 & 0.032 & 0.021 & 0.276 \\
& & & & & & & \\
\hline
\end{tabular}


Table 4

Regression of Price Growth Revisions

on Output and Hours Growth Revisions

\begin{tabular}{|c|c|c|c|c|c|c|}
\hline Included vars.: & $i$ & $\Delta M_{b}$ & $\Delta M_{1}$ & $\Delta M_{2}$ & $s_{H}$ & $\& \Delta M$ \\
\hline & & ressio & s expl & ning 2 & & \\
\hline Coeff. on $\widetilde{\Delta y}^{10}$ & -1.94 & -1.57 & -1.51 & -1.46 & -1.14 & -1.72 \\
\hline & 0.18 & 0.17 & 0.15 & 0.11 & 0.09 & 0.16 \\
\hline Coeff. on $\widetilde{\Delta h}^{10}$ & 2.60 & 1.68 & 1.52 & 1.56 & -0.11 & 2.17 \\
\hline & 0.38 & 0.47 & 0.37 & 0.17 & 0.17 & 0.32 \\
\hline & & rressio & s expl & ining 2 & & \\
\hline Coeff. on $\widetilde{\Delta y}^{\infty}$ & -5.32 & -3.93 & -3.78 & -3.71 & -1.68 & -3.59 \\
\hline & 0.40 & 0.25 & 0.13 & 0.25 & 0.32 & 0.26 \\
\hline Coeff. on $\widetilde{\Delta h}^{\infty}$ & 9.27 & 5.83 & 5.69 & 5.49 & 0.17 & 5.55 \\
\hline & 0.88 & 0.56 & 0.34 & 0.57 & 0.75 & 0.60 \\
\hline
\end{tabular}


Table 5

The Magnitude of Expected Price Changes

\begin{tabular}{|c|c|c|c|c|c|c|c|}
\hline Included vars.: & $i$ & $\Delta M_{b}$ & $\overline{\Delta M_{1}}$ & $\Delta M_{2}$ & $\Delta M_{C}$ & $s_{H}$ & $i \& \Delta M_{b}$ \\
\hline $\overrightarrow{\Delta p}^{\infty}$ on $\overrightarrow{\Delta y}$ & $\begin{array}{l}-1.19 \\
0.068\end{array}$ & $\begin{array}{c}-1.541 \\
0.060\end{array}$ & $\begin{array}{c}-1.475 \\
0.058\end{array}$ & $\begin{array}{c}-1.890 \\
0.092\end{array}$ & $\begin{array}{c}-1.500 \\
0.051\end{array}$ & $\begin{array}{c}-1.739 \\
0.053\end{array}$ & $\begin{array}{r}-1.377 \\
0.066\end{array}$ \\
\hline$\widetilde{\Delta p}^{1}$ on $\widetilde{\Delta y}^{1}$ & $\begin{array}{l}0.184 \\
0.023\end{array}$ & $\begin{array}{l}0.169 \\
0.019\end{array}$ & $\begin{array}{l}0.148 \\
0.020\end{array}$ & $\begin{array}{l}0.052 \\
0.020\end{array}$ & $\begin{array}{l}0.179 \\
0.022\end{array}$ & $\begin{array}{l}0.206 \\
0.020\end{array}$ & $\begin{array}{l}0.174 \\
0.182\end{array}$ \\
\hline$\widetilde{\Delta p}^{1}$ on $\widetilde{\Delta y}^{\infty}$ & $\begin{array}{c}-0.103 \\
0.018\end{array}$ & $\begin{array}{r}-0.101 \\
0.015\end{array}$ & $\begin{array}{c}-0.101 \\
0.016\end{array}$ & $\begin{array}{c}-0.065 \\
0.025\end{array}$ & $\begin{array}{c}-0.118 \\
0.015\end{array}$ & $\begin{array}{c}-0.135 \\
0.013\end{array}$ & $\begin{array}{c}-0.092 \\
0.016\end{array}$ \\
\hline$\overline{\Delta p}^{4}$ on $\overline{\Delta y}^{\infty}$ & $\begin{array}{c}-0.380 \\
0.018\end{array}$ & $\begin{array}{c}-0.412 \\
0.015\end{array}$ & $\begin{array}{c}-0.385 \\
0.016\end{array}$ & $\begin{array}{c}-0.261 \\
0.025\end{array}$ & $\begin{array}{c}-0.410 \\
0.015\end{array}$ & $\begin{array}{c}-0.512 \\
0.013\end{array}$ & $\begin{array}{c}-0.381 \\
0.016\end{array}$ \\
\hline$\widetilde{\Delta p}^{10}$ on $\widetilde{\Delta y}^{\infty}$ & $\begin{array}{r}-0.855 \\
0.018\end{array}$ & $\begin{array}{c}-0.988 \\
0.015\end{array}$ & $\begin{array}{c}-0.927 \\
0.016\end{array}$ & $\begin{array}{c}-0.736 \\
0.025\end{array}$ & $\begin{array}{c}-0.941 \\
0.015\end{array}$ & $\begin{array}{c}-1.133 \\
0.013\end{array}$ & $\begin{array}{c}-0.902 \\
0.016\end{array}$ \\
\hline
\end{tabular}


Table 6

Expected Changes in Monetary Aggregates

\begin{tabular}{|lccccc|}
\hline Included vars.: & $\Delta M_{b}$ & $\Delta M_{1}$ & $\Delta M_{2}$ & $\Delta M_{C}$ & $i \& \Delta M_{b}$ \\
\hline $\operatorname{Corr}\left(\widetilde{\Delta y}^{\infty}, \widetilde{\Delta M}^{\infty}\right)$ & -0.496 & -0.227 & -0.377 & -0.702 & -0.686 \\
& 0.029 & 0.043 & 0.040 & 0.056 & 0.029 \\
$\widetilde{\Delta M}^{\infty}$ on $\widetilde{\Delta y}^{\infty}$ & -0.816 & -0.328 & -0.738 & -0.811 & -1.257 \\
& 0.060 & 0.067 & 0.095 & 0.086 & 0.076 \\
$\widetilde{\Delta M}^{1}$ on $\widetilde{\Delta y}^{\infty}$ & -0.812 & 0.037 & -0.042 & -6.333 & -1.169 \\
& 0.071 & 0.092 & 0.154 & 0.430 & 0.099 \\
\hline
\end{tabular}

